\title{
Energetics, Particle Capture, and Growth Dynamics of Benthic Suspension Feeders
}

\author{
Kenneth Sebens, Gianluca Sarà, and Michael Nishizaki
}

\section{Contents}

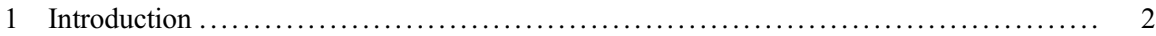

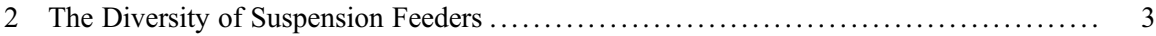

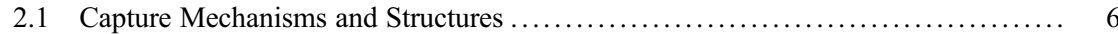

2.2 The Prey Resource for Suspension Feeders ............................... 7

2.3 The Role of Water Movement ............................................ 9

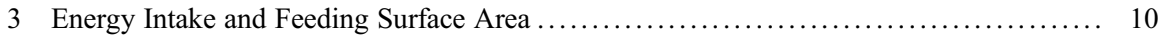

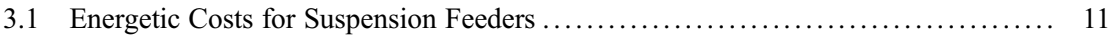

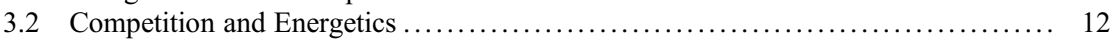

4 Energetics and Growth Models for Suspension Feeders $\ldots \ldots \ldots \ldots \ldots \ldots \ldots \ldots \ldots \ldots \ldots \ldots \ldots \ldots \ldots \ldots$

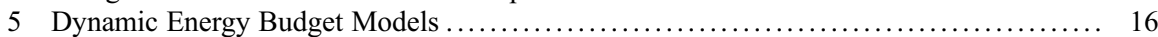

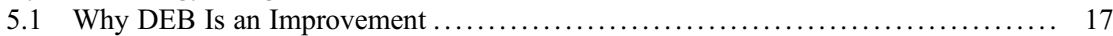

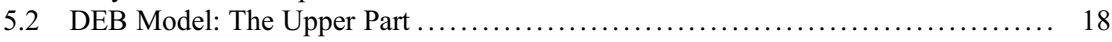

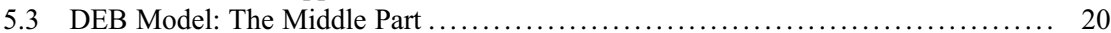

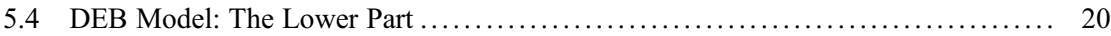

5.5 How to Account the Role of Temperature? .............................. 21

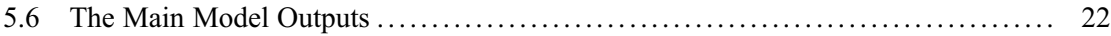

6 Detailed Examples of Energetics for Suspension Feeders …..................... 22

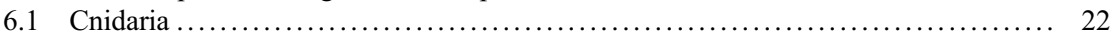

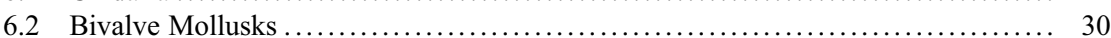

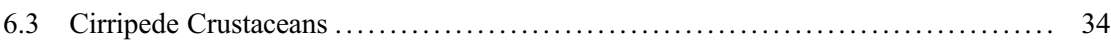

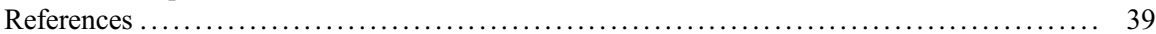

K. Sebens $(\bowtie)$

University of Washington, Seattle, WA, USA

e-mail: sebens@uw.edu

G. Sarà $(\bowtie)$

Università degli Studi di Palermo, Palermo, Italy

e-mail: gianluca.sara@unipa.it

M. Nishizaki ( $\square)$

University of Guelph, Guelph, ON, Canada

e-mail: mtn1@williams.edu

(C) Springer International Publishing Switzerland 2016

S. Rossi (ed.), Marine Animal Forests,

DOI 10.1007/978-3-319-17001-5 17-1 


\section{Abstract}

Marine benthic communities are dominated by suspension feeders, including those actively pumping water, passively encountering particles, or some combination of the two. The mechanisms by which particles are encountered and retained are now well known for a range of water flow conditions and organism morphologies. Recent research has attempted to quantify the energetic components of suspension feeding, including intake of particles, pumping rates, and metabolic costs of these activities. Energetic models depend strongly on environmental conditions, including temperature, flow speed, and food availability, for example. The effects of these variables have been combined for realistic scenarios using dynamic energy budget (DEB) models, and related models to examine components of fitness (growth, reproduction, population increase), for both existing conditions and for conditions expected for future environments. Detailed examples are provided from recent research on bivalve mollusks, cnidarians including sea anemones and corals, and barnacles. These examples cover several major phyla that are often important components of intertidal and subtidal benthic communities. All common phyla of benthic suspension feeders are discussed, though less extensively, especially given the paucity of energetics studies for some of these phyla.

\section{Keywords}

Energetics - Suspension feeding $\bullet$ Benthos $・$ Particle capture $・$ Dynamic energy budget

\section{Introduction}

Assemblages of benthic marine invertebrates are usually dominated by a diverse set of creatures that can be termed suspension feeders, despite quite a wide variety of morphologies, prey types, and modes of capture. Coral reefs, temperate zone rocky reef communities, polar benthic communities, and many types of soft-substrate communities are made up primarily of attached organisms that capture particles from the overlying water column. Some of the best examples of such communities are the dense barnacle zones in intertidal habitats, extensive mussel beds in both intertidal and subtidal habitats, coral reefs dominated by scleractinian corals and sponges, large ascidian aggregations, and subtidal rocky reefs dominated by sponges, octocorals, sea anemones, and others. In such habitats, suspension feeders are often the dominant biomass, as well as ecosystem engineers that build structures used by a diversity of other members of the community, both sessile and motile.

Suspension feeders compete intensely for space on primary substratum, which gives them access to resources in the water moving above the substratum. Ecologists term this "benthic-pelagic coupling" because it is an important mode of transfer for primary production in the water column, to secondary production on the bottom (see also chapter " $>$ Benthic-Pelagic Coupling: New Perspectives in the Animal 
Forests," this volume). Such coupling is an example of a "spatial subsidy" where important resources are delivered to one community or habitat from another, which thus enhances energy and material flow through the former (i.e., local production is subsidized). Production by phytoplankton in large bodies of water can be delivered to the benthos either directly or once it has passed through upper trophic levels such as zooplankton. Primary production in shallow subtidal zones, by kelp for example, can be delivered to deeper communities with minimal primary production by water currents, in the form of kelp fragments or detrital particles. These suspension feeders, in turn, process the subsidies and transfer them in a form that can sometimes be used by other members of the benthic community, including egesta, mucus, fecal material, and sexual products. Pseudofeces and feces, for example, are rich in organic compounds that are acted on by bacteria and made more nutritious for benthic deposit feeders (Galloway et al. 2013).

Passive suspension feeders rely on water currents or wave induced flow to move particles past their capture surfaces. However, active suspension feeders produce their own internal currents that pull water through internal filters; this is particularly important when water flow is minimal but may also be energetically positive even when flow is substantial (Wildish and Kristmanson 2005, review). Some even manage to have it both ways, relying on water flow to induce currents through their body or colony, where particles can be removed from the water internally, then ingested (Vogel 1996). Obviously, water flow is an important component of suspension feeder biology and energetics and will be discussed in some detail in this chapter and in chapters " $>$ Benthic-Pelagic Coupling: New Perspectives in the Animal Forests" and " $\triangleright$ Filter-Feeding Zoobenthos and Hydrodynamics" in this volume.

\section{The Diversity of Suspension Feeders}

Most phyla of invertebrates, and even some vertebrates, have given rise to groups that can be considered suspension feeders. Among the single-celled organisms, there are many which remain attached to a surface and capture particles or other organisms that come into contact with them. The choanoflagellates, for example, use a flagellum to pump water through a mesh-like collar, which then retains particles that are later phagocytized into the cell. These protists, which are thought to resemble the ancestors of sponges, form colonies that presage future multicellular colonies working at a much larger scale. Sponges themselves are active suspension feeders, pumping large volumes of water through their internal channels, sometimes with very obvious jets of high velocity from the osculum. Sponges, however, are also the group in which induced flow was first noticed (chimney effect, Vogel 1996); they save energy by using the water flowing over openings in their highest points to produce a lower pressure that pulls in water through the pores covering their surfaces (ostia). Sponges form thin encrusting sheets, massive globular and vase-like structures, lacework masses, and tubes of glass fibers. They are among the most abundant 
and important members of benthic communities on hard substrata around the world and can be the largest fraction of biomass on some coral reefs.

Cnidarians represent another phylum that has generated many different types of suspension feeders. Hydroids, producing tall and flexible branching colonies, are often among the early colonists on new or recently cleared subtidal surfaces; they comprise numerous small polyps whose tentacles capture a variety of zooplankton. Scleractinian corals employ a similar morphology but have added a large massive or branching calcareous skeleton and polyps with a larger size range, and thus have a larger range of zooplankton and benthic prey they can handle. Sea anemones are basically corals that have lost their skeleton to become solitary motile polyps, some over a meter in diameter, and some with tentacles large enough to capture fish and large swimming invertebrates. The octocorals (soft corals, sea fans, and their relatives) generally have small to medium polyp size, and some are specialized for phytoplankton rather than zooplankton capture (Fabricius et al. 1998 and references therein). Other cnidarian suspension feeding groups include zoanthids, corallimorpharians, benthic scyphozoans, and stalked jellyfish. Hydroids, corals, and soft corals can form dense aggregations of tall colonies that cover large areas of the bottom - the epitome of animal forests.

Bryozoans (Phylum Ectoprocta) are usually not as large as some of the other suspension feeder colonies but can also cover large areas of substratum and produce "forests" on a smaller scale. They have invariably small individual units (zooids) each of which captures prey (bacteria, phytoplankton) via a tentaculate lophophore; ciliary tracts on the lophophores generate currents on a very local scale that bring particles into contact with the tentacles. Bryozoans are also early colonists in many benthic communities and can cover large patches of rock for months to years. Other lophophorate groups such as phoronids, brachiopods, and entoprocts are also common suspension feeders and can be locally abundant.

Polychaete worms (Phylum Annelida) provide a number of examples of benthic suspension feeders, and some even form dense beds or hard structures of cemented tubes. While many polychaetes occupy soft substratum, and suspension feed from burrows or tubes, others build attached structures on hard substrata, including coral reefs; these include the calcareous tubeworms (Family Serpulidae) which can form masses of conjoined tubes, and the feather-duster worms (Family Sabellidae) and Chaetopterids (Family Chaetopteridae) which form large parchment-like tubes or entangled networks of such tubes.

Bivalve mollusks (Phylum Mollusca) are abundant and sometimes large and spatially dominant suspension feeders in benthic communities, pumping large volumes of water and removing phytoplankton and other prey from the water, sometimes effectively enough to deplete the water column near the benthos (Wildish and Kristmanson 2005). Mussel beds dominate intertidal and subtidal habitats worldwide, and oyster reefs can be expansive and can even convert soft-substrate habitats to hard reefs. In the Chesapeake Bay, USA, it has been argued that oysters structure the planktonic community, and in fact could remove most of the suspended particulates from the whole bay in a matter of days. Clams form dense aggregations in 
soft-substrate habitats and some in hard-substratum communities, and scallops can also be important contributors in both habitat types.

Also among the mollusks, some gastropods such as the vermetids are the dominant taxa of bio-constructed intertidal rocky reefs in the Red Sea and Mediterranean (chapter " $\triangleright$ Drawing the Line at Neglected Marine Ecosystems: Ecology of Vermetid Reefs in a Changing Ocean" of this volume). In particular, the Mediterranean vermetid Dendropoma (Novastoa) petraeum associated with the encrusting red algae Neogoniolithon brassica-florida are suspension feeders relying for their diet on less than $1 \mathrm{~mm}$ particles captured by mucus nets which are spread by wave action over the substratum. Hauling the net occurs many times per hour throughout the day. The spatial distribution, feeding, and reproduction of the vermetid gastropod Dendropoma maximum have been described; although $D$. maximum is not a specialized filter feeder, the highly developed ciliary mechanisms suggest that filtering may be an auxiliary feeding method (Hughes and Lewis 2009).

Considering the high intertidal zone, it is clear that barnacles (phylum Arthropoda, subphylum Crustacea) are the most successful suspension feeders in the physiologically stressful zones covered by water only a few hours a day and baked by the sun or frozen solid for days. Farther down the intertidal, they are still among the most abundant fauna in all zones, sometimes settling in almost continuous mats when disturbances have created cleared space on rocky shores. In subtidal communities, barnacles can still be among the most common suspension feeders and dominate space in some habitats. They also achieve very large individual sizes subtidally, some individuals larger than a human fist. On coral reefs, barnacles are important in intertidal zones and in cryptic reef habitats though they are usually a small part of reef biomass. Among the motile crustaceans, there are other suspension feeding groups, including certain crabs and amphipods.

Echinoderms include several groups of important suspension feeders, such as basket stars and brittle stars (ophiuroids), feather stars (crinoids), sea cucumbers (holothurians), and some sea stars (asteroids). Sea urchins also suspension feed, capturing large particles such as fragments of macroalgae as well as smaller detrital material. Although most echinoderms are motile suspension feeders, they often form aggregations that are stationary for long periods of time. Ophiuroids in particular can form dense beds on both soft and hard substrate surfaces, with fields of waving arms. Holothurians form dense subtidal aggregations as well, sometimes with their tentacles crowns filling the available space and forming another distinct "animal forest."

Ascidians (Phylum Chordata, Subphylum Urochordata) often comprise another spatial and biomass dominant group on subtidal reefs and certain intertidal habitats. Ascidians form colonies of small zooids, groups of zooids connected by stolons, or large solitary zooids. One large intertidal species (Pyura stolonifera), in northern Chile (Castilla et al. 2000), can form dense and thick intertidal beds of solitary zooids connected together by adhesion of their tunics. Individuals can be almost $30 \mathrm{~cm}$ tall, and the bed itself tough enough to withstand humans walking on it. These monospecific communities occupy the mid-intertidal zone usually claimed by mussels. Large solitary ascidians are also common on 
coral reefs, as are the various colonial forms. Subtidal rock in the temperate zones of the world is frequently covered by both colonial and solitary ascidians, many of which are fast growing, and some are problematic invasive species around the world.

\subsection{Capture Mechanisms and Structures}

Ocean water contains entire communities of organisms as well as nonliving particulates and dissolved substances that can be utilized by benthic suspension feeders (Wildish and Kristmanson 2005). Capturing particles from moving water presents a number of difficulties, however, since the suspended particles can be present at rather low numbers and mass per unit volume. Furthermore, the smaller the particles and capture devices involved, the more difficult it becomes to separate particles from the water. Suspension feeders have developed several different mechanisms for accomplishing this separation, which operate on particles ranging from tiny bacteria to creatures many centimeters in diameter (Fig. 1). It was recognized in the 1970s that suspension feeders are mostly not acting like sieves, i.e., they do not pass water through a filter that retains all particles above a certain pore size (Rubenstein and Koehl 1977). Although such mechanisms exist, most suspension feeders (or filter feeders) capture particles from the water by causing those particles to contact filter

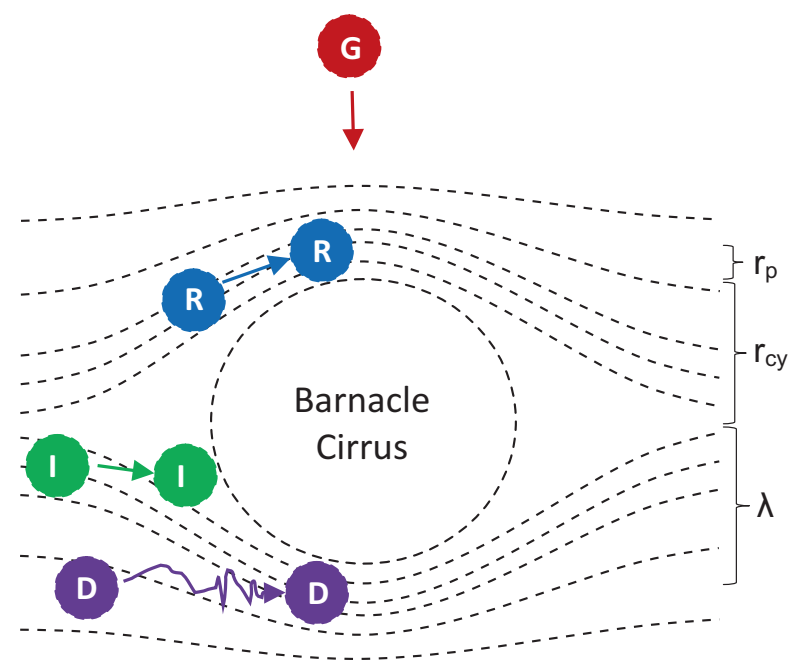

Fig. 1 Mechanisms of aerosol particle capture (After Shimeta and Jumars 1991). Direct interception $(\boldsymbol{R})$ of a particle from flowing seawater as it moves along a streamline around the filter element. Inertial impaction (I) occurs when the momentum of a cyst causes it to deviate from the path of a streamline and contacts the cirrus. Gravitational deposition $(\boldsymbol{G})$ can occur when sedimenting particles contact the element. Diffusional deposition (D) applies when particles exhibiting random paths collide with water molecules and are collected when they contact the element. $\lambda$ is the effectively swept region $(\mathrm{m}), \mathrm{r}_{\mathrm{c}}$ is the radius of the cylinder $(\mathrm{m})$, and $\mathrm{r}_{\mathrm{p}}$ is the particle radius $(\mathrm{m})$ 
elements, even though the spaces between such filter elements can be much larger than the particles. These mechanisms were first described for mechanical air filters (aerosol filtration) but most work equally well in water and have been demonstrated in a variety of marine suspension feeders (Rubenstein and Koehl 1977; Shimeta and Jumars 1991; Jumars 1993).

Mechanisms of filtration have been reviewed extensively (Shimeta and Jumars 1991; Denny 1988), and there are many details and modifications that are important; we cannot cover them all here, so we will strive to give a useful overview that should encourage those interested to delve further. First, and simplest, particles suspended in water can simply impact a filter element (e.g., tentacle) because the diameter of the particle extends far enough from the streamline carrying the particle, such that it touches the tentacle (direct interception). Second, particles travelling fast enough carry inertia that causes them to keep moving straight ahead though the fluid around them deviates around an object (the bug on the windshield effect). Third, particles can be denser than the fluid they are in and gravity will cause them to settle out onto feeding surfaces. Fourth, there can be electrostatic attraction between the particle and the feeding structure (LaBarbera 1984), although this is minimal in seawater and may affect retention rather than attraction. Fifth, sieving can occur when particle diameters are larger than holes in a membrane or other structure. Sixth, diffusional deposition occurs when a particle moves out of its streamline by its own activity (swimming, for example) or by random motion, and thus encounters a capture surface. These mechanisms will be discussed in greater detail in the following sections, as they apply to specific suspension feeders.

\subsection{The Prey Resource for Suspension Feeders}

Suspension feeders have a variety of prey available from the overlying water column, but mechanisms that work well for one prey type may not work at all for prey of other sizes or swimming abilities. Organic particulates come in all sizes from hydrated gels to fragments of larger organisms $(<1 \mathrm{um})$, and such particles often contain enough nutrition to be worth capturing. Bacteria range in size from $<1$ um to $>3 \mathrm{~m}$ (Jumars 1993) and are also among the smallest particles used by suspension feeders. Sponges, corals, and several other groups have been shown to capture bacteria and derive significant energy and nutrients from that size range of prey. Since particles only a few microns in diameter are much smaller than the spaces between most filter elements, it is clear that they must be captured by means other than sieving. They are also not likely to be substantially more dense than water, although some may be motile enough to affect capture rates. Such particles are usually captured by direct interception and retention on mucus strands or delivery in ciliary flow fields followed by adhesion to cilia alone (Romero et al. 2010). Sponges, however, have sieve-like collars on the choanocytes with pores small enough to retain prey of this size. 
Phytoplankton often comprise the majority of planktonic particles and sometimes of biomass as well. They come in a great range of sizes, from a few microns to forms visible to the naked eye. A large fraction of suspension feeders specialize on phytoplankton, while still being able to capture smaller particles such as bacteria, detrital material, and small zooplankton and larvae. Bivalve mollusks, bryozoans and other lophophorates, ascidians, most echinoderms, barnacles, and some octocorals are among the groups that focus on phytoplankton. Phytoplankton are also quite diverse in shape, nutrition, skeletal material, and toxicity. Therefore, suspension feeders show distinct preferences and avoidance of certain types. Every suspension feeder studied shows such selectivity and has evolved mechanisms to detect and accept or reject individual prey items. This is also true for motile suspension feeders, such as copepods, which detect, contact, and assess each particle passing their antennae before deciding to capture and ingest it or let it go by.

Other groups of suspension feeders clearly focus on zooplankton as their primary food resource, though they may have the ability to capture other particle types. Corals, for example, are mostly specialists on medium to large zooplankton (Sebens et al. 1996b, 1997, 1998; Palardy et al. 2006; Houlbreque et al. 2009 review) but can also capture detrital particles (Mills and Sebens 2005; Anthony and Fabricius 2000) and bacteria (Sebens 1987a; Houlbrèque and Ferrier-Pagès 2009 reviews). Most corals do not capture phytoplankton, but certain octocorals have switched to that resource predominantly (Fabricius et al. 1998). Other cnidarians such as hydroids, sessile scyphozoans, zoanthids, corallimorpharians, sea anemones, and cerianthids also appear to be zooplankton specialists. Zooplankton captured by suspension feeders have a huge size range, from $20 \mu \mathrm{m}$ to many centimeters; microzooplankton (20-200 $\mu \mathrm{m}$ size fraction) captured include groups such as rotifers, ciliates, flagellates, and small larval stages.

Even larger prey are also captured by suspension feeders, including nekton and mobile benthos. Certain coral species with very large polyps, many sea anemone species, and a few other cnidarians routinely capture such prey. This might be considered direct predation rather than suspension feeding, except that even these large particles are affected by water movement and are often carried to the tentacles by water flow, although their own swimming behavior also influences capture. Various large swimming crustaceans (shrimp, mysids, fish) are captured by corals and anemones (Sebens et al. 1996b, 1997) and benthic crustaceans and fish often enter the water column temporarily and are then captured by cnidarians. Some of the larger sea anemones depend on wave action or the activity of predators to dislodge benthic prey, which are then carried to them by water flow and gravity (e.g., mussels, Sebens 1982, 1987a, b, reviews). Some of these "particles" are well over $10 \mathrm{~cm}$ long, about the same as the diameter of their predators. Few other phyla have developed specializations for such large prey, although predatory sponges are one example. Sea urchins that capture drift algae, which can also be many centimeters long, are another example, and in this case the prey can be much larger than the predator. 


\subsection{The Role of Water Movement}

Suspension feeders capture particles from moving water by using the water's intrinsic motion (passive suspension feeders), by causing water motion via some form of pumping (active suspension feeders), or by using a combination of both methods. Organisms that use induced flow may be passive at one level, but active at a smaller scale where particles are actually removed from the water. For passive suspension feeders, the ambient flow regime is critically important and may determine whether they can live there at all or whether their capture mechanisms will function effectively. Clearly, sea anemones that capture zooplankton from unidirectional currents, for example, would do very poorly in large intertidal waves. Flow regimes can be characterized by flow speed and direction as well as by the Reynolds number, a dimensionless index that depends on velocity, size of structures, and viscosity of the fluid. High Reynolds numbers occur with high velocity, larger structures, and lower viscosity. Low Reynolds number flow examples would be small capture structures in low flow, capturing small particles; the fluid viscosity becomes more important in this type of flow, and it is harder to move water between filter elements. Motile suspension feeders such as copepods are always dealing with this type of flow at the scale of their capture structures (Koehl and Strickler 1981), as are many of the sessile species we are considering here.

Most passive suspension feeders utilize unidirectional currents, since that is the normal condition for most of the world's subtidal benthic habitats. These creatures present a capture surface to the flow and remove particles as they encounter the filter elements on that surface. There are many mechanisms that function well in such flow, depending on the size of particle to be removed. Other passive suspension feeders rely on wave induced flow to carry prey to their feeding structures. Such flow is oscillatory and is often combined with unidirectional flow, especially in deeper habitats where the wave component is attenuated. For a passive suspension feeder, equal flow in two directions, for several seconds each direction, is at least equivalent to unidirectional flow for the same total time. Many studies of water flow in benthic habitats concentrate on the unidirectional element and filter out the bidirectional wave induced flow (vector-averaged flow). This is acceptable to calculate how far particles or larvae are carried in a given time unit, but it is not appropriate for calculating the arrival rate of particles impinging on suspension feeders. To calculate the flow past a suspension feeder or filter element, the magnitude of flow independent of direction should be calculated each fraction of a second (nonvector averaged), and those flows summed for the time period in question. Oscillatory flow can give a suspension feeder multiple chances to capture the same particle and can interfere with prey swimming and escape behavior, such that suspension feeders capture more prey in oscillatory than in unidirectional flow of the same total volume of water moved (Sebens 1987a, 1997, review).

The magnitude of flow is also a very important aspect of the flow regime. Subtidal benthos can be subjected to unidirectional currents well over a meter per second, and intertidal or shallow subtidal habitats experience wave-induced flows at least ten 
times that speed, up to $30 \mathrm{~m} \mathrm{~s}^{-1}$. Such high flows represent a limitation for both survival and effective feeding, and most animals that live in such habitats have mechanisms to contract the body and thus reduce drag as well as very strong attachment to the surface (high Reynolds number flow). Despite the high forces involved, high flow habitats can be excellent locations for suspension feeders. Coral growth is highest in the shallow reef zones experiencing high light and high waveinduced flow; Charles Darwin recognized early on that high flow conditions produced the most rapid reef growth. There are numerous mechanisms to allow particle capture in high flow. Having a stout body and tentacles, which can function in high flow while limiting drag forces, works for large sea anemones in crashing surf (Sebens 1987a, b, reviews). They not only survive but benefit from the wave action dislodging and transporting prey. Coral colonies with dense thickets of short branches reduce flow within the colony such that some polyps are able to capture prey even when leading edge polyps are not (Sebens et al. 1996a). Certain bryozoans benefit from neighboring colonies by experiencing reduced flow also (Okamura and Partridge 1999).

On the other end of the spectrum, some suspension feeders must deal with very slow flows, small particles, and a comparatively viscous fluid at that scale (low Reynolds number flow). In fact, all of the suspension feeders capturing bacteria, phytoplankton, and small detrital particles generally function in a low Reynolds number environment. For such creatures, moving water between filter elements, and removing particles from water, becomes increasingly difficult; appendages act more like paddles than like rakes (Koehl and Strickler 1981). The classical example of this phenomenon is trying to remove a fly from a jar of honey with a fork; the honey does not move much between the tines of the fork, and the fly is pushed ahead of the fork. Two forks working against each other are much more successful, and that is how some crustaceans deal with the problem by squeezing the water through the filter and retaining the prey (Koehl and Strickler 1981).

\section{Energy Intake and Feeding Surface Area}

For passive suspension feeders, capturing particles from moving water involves presenting a capture surface perpendicular to that flow. Such structures can take the form of a paddle or fan (sea fans, some hydroids), cylindrical branches (octocorals, scleractinian corals), or elongate filaments (whip corals). At a smaller scale, each tentacle, pinnule, or other filter element is also oriented perpendicular to flow, which increases the probability of particle interception. The larger the crosssectional surface area of these feeding surfaces, the more drag will be experienced, sometimes enough to damage or dislodge the entire colony (e.g., sea fans in storms). The trade-off between increased prey capture and decreased survival is probably one of the most important processes determining the shape and size of suspension feeders and their parts. Certain suspension feeders, such as cnidarian medusa, trail long tentacles parallel to the direction of motion and may rely on prey swimming to effect encounters. 
For active suspension feeders, water is pumped into the body and through a capture structure, which may include mucus strands or nets, then is ejected. In ascidians, particles move through the stomata in the pharynx, with ciliary tracts on either side providing a feeding current, and particles are retained on a mucus net produced by the endostyle, then rolled into a cylindrical mass that is ingested. In bivalves, water is pumped across a complex gill surface, and particles are sorted by ciliary tracts, with some retained on mucus and ingested. Here too, a feeding surface is presented to flow but it is generally parallel to flow, although the individual mucus strands may be perpendicular to flow. The entire gill surface, for example, will determine the potential for particle ingestion. Pumping rate also influences the number of particles coming into contact with these structures, and thus helps determine energy intake. Here too, there should be some optimal flow speed across the capture surface that increases encounter rate, without causing too many particles to be missed or lost after capture.

Energetics models often consider intake to be a function of capture surface area (Sebens 1979; Kooijman 2010); for sheet-like colonies, surface area may increase linearly with biomass because growth involves producing more units of similar size and shape. For creatures that grow as cylinders, spheres, or other solids, surface area is expected to increase less rapidly than mass or volume (e.g., 0.67 power of mass). This is true only if growth is isometric. For allometric growth, surface area could be proportional to mass or volume for at least some size ranges. The trade-off between intake and drag forces could produce allometries that actually decrease the feeding surface to mass ratio as organisms get larger.

\subsection{Energetic Costs for Suspension Feeders}

Passive suspension feeders do not spend energy to move water past their surfaces; however, there is some cost involved in maintaining an expanded condition in flowing water and to producing the mucus, nematocysts, and other expendable materials used in feeding. Invertebrate suspension feeders are also mostly metabolic conformers, meaning that they respire at a greater rate when there is more oxygen in the ambient water adjacent to their tissues. An expanded cnidarian, for example, has a higher metabolic rate than a contracted one in part because expansion brings more surface area into contact with oxygen-rich water. The water inside a contracted body is usually quite depleted of oxygen. Anything that causes the animal to be more active (pumping), produce more feeding materials, or come into contact with more oxygen molecules (water flow, photosynthesis) increases the metabolic rate. Active digestion of prey also increases metabolic rate; this is termed "specific dynamic action." When water is moving slowly, the diffusional boundary layer above tissue surfaces can be very low in oxygen even when the concentration in the bulk flow is quite high.

Pumping is an important energetic cost for active suspension feeders, though sometimes they can avoid it by using induced flow when conditions warrant this. Ascidians can use orientation of their incurrent and excurrent siphons to generate 
induced flow, and the tall columnar shape of many sponges also produces a strong induced flow (Vogel 1996, review). Barnacles, which pump water through their filters by extending and retracting their legs, sometimes stop that activity when water flow is high and unidirectional (Trager et al. 1990), becoming temporary passive suspension feeders. Even in slow moving water, sponges process huge volumes of water, with flows generated by flagella of the choanocytes; the result can be a vertical plume of exhalant water that is easy to see by introducing dye. Mussels and other bivalve mollusks also pump a lot of water through their siphons, with the pumping rate being accompanied by increased metabolic cost (Sebens 1987b, review).

\subsection{Competition and Energetics}

Most of the suspension feeders considered here are attached to hard surfaces, and thus must compete with other organisms for this primary space, a very limited resource. In some cases, an entire encrusting colony occupies a large fraction of the primary space, and in other cases attachment is by a small structure that allows the rest of the animal to protrude well above the substratum and above many of its competitors. Competing for space is also competition for access to the food resource in the water column and sometimes access to light. Because of this, there is a very obvious trade-off between energetic considerations and competitive ability. For example, it might be possible to determine the best size, shape, and branch spacing for capturing a certain class of particles at a range of realistic flow speeds. However, any particular suspension feeder of interest may not conform to that prediction because of interactions with competitors (including intra-specific neighbors).

One such example is the coral Agaricia tenuifolia, which differs greatly in branch size, shape, and spacing. This species often grows in dense stands with other colonies of the same species and a few others. Once a colony has filled available space, and is limited by its neighbors, it may be better to pack in more branches in the space attained, even if a wider branch spacing would be better for light or plankton capture (Helmuth et al. 1997; Sebens et al. 2003). Given a limited amount of space, more tissue can be produced, and ultimately more larvae released, in the former case. Another consideration for corals is polyp size; a colony with very small polyps has a high surface area to biomass ratio, which can maximize small particle or light capture. However, large polyps are more successful competitors for space using either sweeper tentacles or mesenteric filament extrusion (extracoelenteric digestion) (Lang and Chornesky 1990; Wellington 1982). There may thus be a stable coexistence between branching corals with small polyps but rapid growth rate and those with large polyps that can defend space from overgrowth (Sebens 1997).

Forming a canopy of branches well above the rest of the benthos is an excellent way to avoid some of this competition as well as to access prey in faster moving water higher within the benthic boundary layer. However, once 
such erect structures become abundant, they can compete among themselves for canopy space and they may also have an effect on the ambient flow regime. This effect can be negative at lower flow speeds, where downstream colonies experience much reduced flow, but positive at high flow speeds, where isolated colonies or branches experience flows too high for efficient particle capture (Sebens et al. 1996a; Okamura and Partridge 1999). In many benthic communities, substratum space is fully occupied by encrusting forms, and there can be one or more canopy levels above that. Hydroids and bryozoans, for example, often comprise a canopy level a few centimeters above rock surfaces, whereas tall sea anemones, gorgonians, and other erect forms reach tens of centimeters to over a meter into the water column.

\section{$4 \quad$ Energetics and Growth Models for Suspension Feeders}

Energetic models were first applied to active suspension feeders such as bivalve mollusks (e.g., Bayne and Widdows 1978) where energy intake was measured from clearance rates in laboratory aquaria, and metabolic rate was determined for a range of pumping rates. For bivalves, energy intake was found to scale with body mass as a surface area relationship or at an even lower power of mass $(<=0.67)$ while energetic cost had a higher power relationship $(>=0.8)$, suggesting that bivalves are more productive at converting energy to mass or reproductive output at sizes well below their maximum possible size (Sebens 1987b, review). These models also defined a "scope for growth" (Warren and Davis 1967) which is the difference between intake and cost, although reproduction was considered a cost in these models, thus the term "scope for growth." If reproduction is taken out of that equation and only maintenance costs used, this becomes a "scope for growth and reproduction" [or "energy surplus"] which could, for example, all be used for reproduction. The difference between intake and cost is a useful measure of environmental suitability, especially if compared over a range of sizes.

For passive suspension feeders, energetic models also indicate that intake is related to surface area of the feeding apparatus, whereas metabolic costs generally scale as a higher power of body mass (Sebens 1979, 1982). For such creatures, this also suggests that there is some maximum size where all energy intake would be used to meet metabolic demands, and none would be left for growth or reproduction. Furthermore, these simple models could be used to predict an energetically "optimum" size which provides the greatest difference between intake and cost (Fig. 2). On purely energetic grounds, growth beyond that size would be maladaptive and growth should stop there to maximize reproductive output (Sebens 1979). Of course there are nonenergetic reasons why any particular organism might benefit from stopping growth at a smaller size (e.g., high predation on larger sizes) or grow beyond this energetic optimum (e.g., competitive advantage). To determine the actual optimum based on average individual fitness, the energetics model must be combined with a life history model that calculates the potential intrinsic population growth rate for hypothetical organisms with each life history strategy (Sebens 2002; 

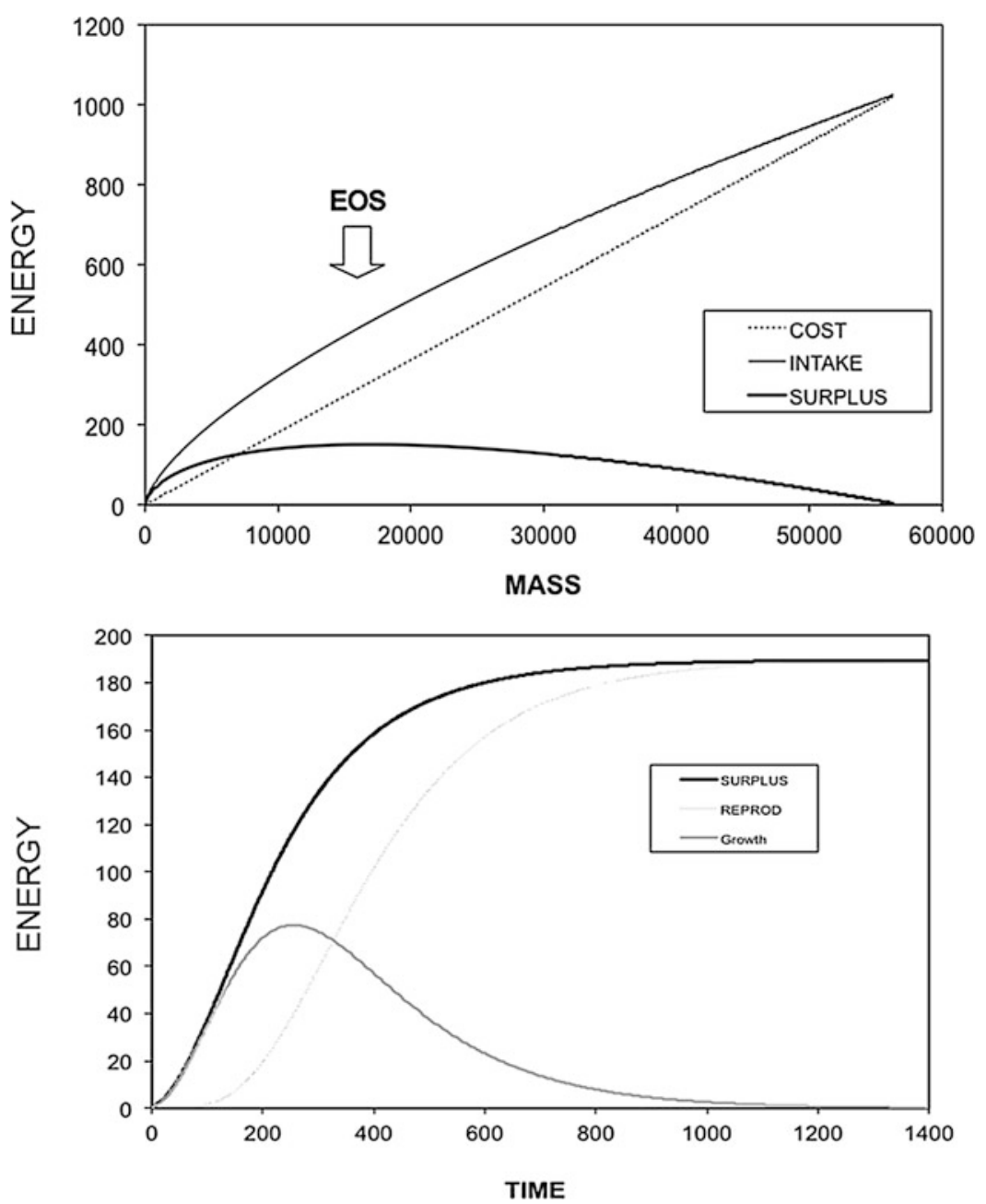

Fig. 2 Energy intake and cost functions for a suspension feeder, where intake scales as a function of surface area and cost scales as a function of mass. Energy and mass are in arbitrary units. EOS is the energetic optimum size (mass) where the energy surplus, the difference between intake and cost, is the greatest. The lower panel shows allocation of the energy surplus to reproduction and growth during an individual's lifetime (Replotted from model in Sebens 2002)

Sarà et al. 2013a, b; Carrington et al. 2015). This per capita growth rate (expressed as $\mathrm{r}$ or $\lambda$ ) can be considered an estimate of individual fitness or could be used for population projection; is the population expected to increase or decrease and at what rate under any set of conditions?

The relevant energetics and growth models were first developed by Putter and von Bertalanffy in the 1920s and 1930s (Sebens 1987b; Kooijman 2010, reviews). The basic formulation is: 


$$
\mathrm{E}_{\mathrm{s}}=\mathrm{k}_{1} \mathrm{Mc}_{1}-\mathrm{k}_{2} \mathrm{Mc}_{2}
$$

where $E_{s}$ is energy per unit time (surplus); $c_{1}$ and $c_{2}$ are exponents of mass (M) for assimilated intake and energetic cost, respectively; and $\mathrm{k}_{1}$ and $\mathrm{k}_{2}$ are fit constants for intake and cost, which change with environmental conditions (e.g., temperature, food availability, or salinity; Sebens $1987 \mathrm{~b}$ review). Energetic cost comprises respiration, excretory losses, and production of lost material such as mucus, exudates, and expendable parts (e.g., nematocysts). The exponents $\mathrm{c}_{1}$ and $\mathrm{c}_{2}$ are scaling factors, part of the growth program of a given species, although environmental effects can influence these also (e.g., as morphology changes). $E_{\mathrm{s}}$ is energy surplus, intake minus cost, but not including reproductive costs (in the cost term). This value can be converted to units of mass (growth) and/or to units of reproductive output (mass, gametes) and can thus become the basis for a growth equation. Reproductive costs include construction of gonad, metabolic rate of gonad tissue, construction of gametes, and metabolic rate of gametes. Depending on how total metabolic rate is measured (i.e., with or without gonads present), some of those costs could be hard to separate out. However, we can more easily measure gamete output as a separate cost or as a separate category of mass increase. The maximum size possible occurs when intake equals metabolic cost, but this size allows no energy for reproduction.

If all reproductive costs are included in the cost term of the equation for energetic surplus, or scope for growth, there is no way to predict an optimum size. With both somatic growth and reproductive output dependent on $E_{s}$, the predicted optimum size occurs when $E_{s}$ is at a maximum (i.e., where the derivative of (Eq. 1) is zero, $\left.\mathrm{dE}_{\mathrm{s}} / \mathrm{dM}=0\right)$ :

$$
\mathrm{M}_{\mathrm{opt}}=\left(\mathrm{c}_{2} \mathrm{k}_{2} / \mathrm{c}_{1} \mathrm{k}_{1}\right)^{\left(1 /\left(\mathrm{c}_{1}-\mathrm{c}_{2}\right)\right)}
$$

This represents the maximum amount of energy (per unit time) that can be used to construct somatic tissues, reproductive tissues, and gametes (Sebens 1979, 1982). If growth stops at this point, maximum reproductive output occurs, and further growth would not be advantageous unless other fitness parameters are affected.

Neither the maximum nor optimum size predictions apply to whole colony energetics, where feeding surfaces and tissue mass are added as nearly identical units; in such cases, both intake and cost theoretically scale directly with colony mass $\left(\mathrm{c}_{1}=\mathrm{c}_{2}=1.0\right)$, although colony growth form could lead to allometric relationships. Colonies growing as a flat sheet are most likely to have intake and cost values that scale directly with whole colony mass, whereas complex branching colonies probably would not. Polyps on the lower or interior side of such colonies may experience lower food availability (Sebens et al. 1996a) as well as lower light and possibly oxygen concentration at night. Both intake and cost would thus be location dependent and neither would likely scale directly with whole colony mass. Sebens (1979) explored the energetic consequences of dividing up a given colony mass into units of different size, using the same equations presented above. This model predicted that the smallest possible unit size will 
provide the greatest energy surplus for the whole colony, and thus units should be just large enough to capture their prey and produce offspring. But, what happens when there is a range of prey sizes available? If we assume that larger units capture larger prey, and prey size is normally distributed, it turns out that having polyps just above the mean prey size is optimal. Above that size the colony is sacrificing feeding surface area, and below that size polyps are potentially losing the most abundant prey.

Note that the above equation for optimal size depends on fixed values of $\mathrm{c}_{1}, \mathrm{c}_{2}, \mathrm{k}_{1}$, and $\mathrm{k}_{2}$ which is certainly not the case in the real world, though average values might suffice. In reality, $\mathrm{k}_{1}$ and $\mathrm{k}_{2}$ derive from multiple functions incorporating food availability, and environmental temperature, and could include many more factors affecting both intake and cost. $\mathrm{c}_{1}$ and $\mathrm{c}_{2}$ are determined by the morphological and physiological scaling of a particular species. However, we know that both shape and physiological functions show phenotypic plasticity and can thus be determined by environmental conditions. While these simple energetic models are useful, much more complex models that incorporate temporal variation in physical conditions and food availability are needed to produce accurate models of growth.

\section{$5 \quad$ Dynamic Energy Budget Models}

Among the more recent methods of dealing with organism energetics, the most reliable and accepted approach is based on the dynamic energy budget theory (DEB; Kooijman 2010), which mechanistically depicts temperature-dependent metabolic processes with precision and enables us to make accurate predictions of an organisms' growth performance and other life history traits. Such an approach can be useful in an era when the pace of climate change (and the related observed and projected range shifts, Pacifici et al. 2015) is expected to be even greater in aquatic ecosystems compared to those on land. While intertidal habitats are extremely chemo-physically variable, due to tides which connect them with highly variable terrestrial environmental conditions, most subtidal habitats are comparatively stable over time from a chemical and physical point of view. As a main consequence, subtidal marine organisms are more narrowly adapted to such small changes of conditions in the surrounding environment. The DEB model, incorporating direct relationships between both metabolism and temperature and available food is able to capture such small influences of habitat change on organismal traits.

DEB is the core of functional trait-based mechanistic bioenergetics models which are based on characteristics of a species' fundamental niche (Sarà et al. 2011, 2013, 2014a, b). Such models provide the information (i.e., quantitative predictions about life history traits of one species, e.g., fecundity, body size, growth rate) necessary for predictions of where a species can persist, or not, and how it reacts, within the species-specific physiological boundaries, to environmental variability. This predictive ability meets one of the most important needs in ecology, i.e., being able to predict species abundance along spatio-temporal environmental gradients. 
Mechanistic-based models provide the best and the most reliable quantitative information (and predictions) to determine how biological processes and life history strategies of individual organisms are altered by changing external conditions, and how these scale up to determine population dynamics and, ultimately, the success and distribution of species.

The development of predictive mechanistic species distribution models based on bioenergetics, with the ability to explore the vulnerability of marine species to environmental changes, supports the realism of the predictions in a context of climate change. For instance, it can help us foresee and anticipate ecological and economic costs of biological invasions, providing useful guidance for planning, conservation management and control strategies (Richter et al. 2013; HamaouiLaguel et al. 2015; Chapman et al. 2016), increasing the predictive capability with respect to where and when commercial stocks will become more vulnerable to collapse. It can also serve as an early-warning system (sensu Munroe et al. 2012) addressing successful management of resource exploitation and for the maintenance and enhancement of resilience in the context of the ecosystem-based management approach (Pikitch et al. 2004; Berkes 2012).

\subsection{Why DEB Is an Improvement}

DEB comprises a complete theoretical asset, at the whole organismal level, to link habitat, functional traits, and life history of any living organism. It allows one to mechanistically investigate: (i) how any species manages the available energy from the habitat and (ii) how the utilization of this energy is prioritized, i.e., the important choices that one organism has to activate (often not consciously) to optimize fitness over its life span. These two aspects are based on strict physical, chemical, and thermodynamic laws (the so-called first principles) governing the functioning of the world. Indeed, we know that every organism on the planet follows similar rules to gain energy from its surroundings and to transform it into biomass (e.g., tissues, skeleton, etc.) and gametes (e.g., eggs), while avoiding mortality for as long as possible.

The mechanistic properties of this approach rely on energy and matter flows from the habitat through organisms. But, flows of energy and matter are subject to conservation laws (Kooijman 2010) and, consequently, they are traceable (and budgetable) processes that can be used to predict the functioning of each species (e.g., any suspension feeder) and thereby the magnitude and variability of life history traits (Carrington et al. 2015). By analogy, any organism can be conceptualized as a washbasin (M. Kearney; unpublished; Sarà et al. 2013a). Energy flowing from the habitat (here, the large water container at the back of the washbasin) is modulated by numerous functional traits (the tap; e.g., the Holling functional response accounting for mutually exclusive functions such as searching, handling, ingestion of the food available, and assimilation). It reaches the washbasin and accumulates into reserves (the water present in the washbasin; i.e., stored as metabolites such as proteins, lipids, carbohydrates). Two drain pipes of different diameter leave the washbasin and 
allow the water (energy reserve) to reach two main (virtually separate) containers: the first is that of structures (i.e., the body structures) accounting for most of the flow rate (the so-called kappa); the second pipe is narrower than the first and supplies energy to the reproduction container (i.e., 1-kappa).

These two flows are connected by a trade-off (the kappa rule; Kooijman 2010) and are directly linked to the amount of reserves, which depends on the internally available energy managed by the organisms which, in turn, depends on the ability of organisms to manage the amount of energy acquired from the habitat. If, for some reason, the washbasin empties, there is no more energy to refill the two containers, and structure and reproduction both decline, based on outflows that represent maintenance costs. This situation will have important repercussions on organismal ability to cope with environmental variability (e.g., obtaining food from the habitat, interacting with other organisms, sustaining an immune-defence system, and producing gametes). While not every organism possesses vascular supply networks, all organisms mobilise internal energy and store material before metabolites are transported to fuel metabolism. The manner and the efficiency with which energy flows through an organism vary according to its metabolism; thus, energy flow is greatly affected by body size. In DEB theory, the structural volume $V$ (i.e., the cube of volumetric length) represents body size and the conversion between physical length $L$ and $V$ is performed by including the shape coefficient, a dimensionless quantity (Kooijman 2010).

In a DEB context, volume and surface area play crucial roles in energetic exchanges and fluxes. For instance, acquisition rates are considered proportional to surface area (displayed in curved brackets), while maintenance rates requiring energetic costs are usually related to volume or mass (square brackets). The standard DEB model can be roughly partitioned into two separate large compartments: one (upper compartment in Fig. 3) dealing with feeding process that describes how energy coming from food is stored as metabolites (e.g., stored proteins, lipids, carbohydrates) and another (lower compartment in Fig. 3), in which the energy is allocated to maintenance and transformed into structures (i.e., growth) and offspring (i.e., reproduction). The link between the two parts is represented by a third compartment, the reserves, in which all the energy coming from the upper part is first stored, then made available for direct use (and is then available for the lower part). Organismal mass is usually a linear function of volume, and vice versa.

\subsection{DEB Model: The Upper Part}

Given a constant supply of food, the amount a suspension feeder can acquire is determined by the availability of food (delivery rate) and the rate at which the food itself can be removed from the environment (Fig. 3). In bivalves, for example, the flow of particles retained through filtration is equivalent to the product of clearance rate (CR) by the total amount of food $\left(\mathrm{X}_{\mathrm{n}}\right)$. Once they arrive on the gills (of bivalves), 


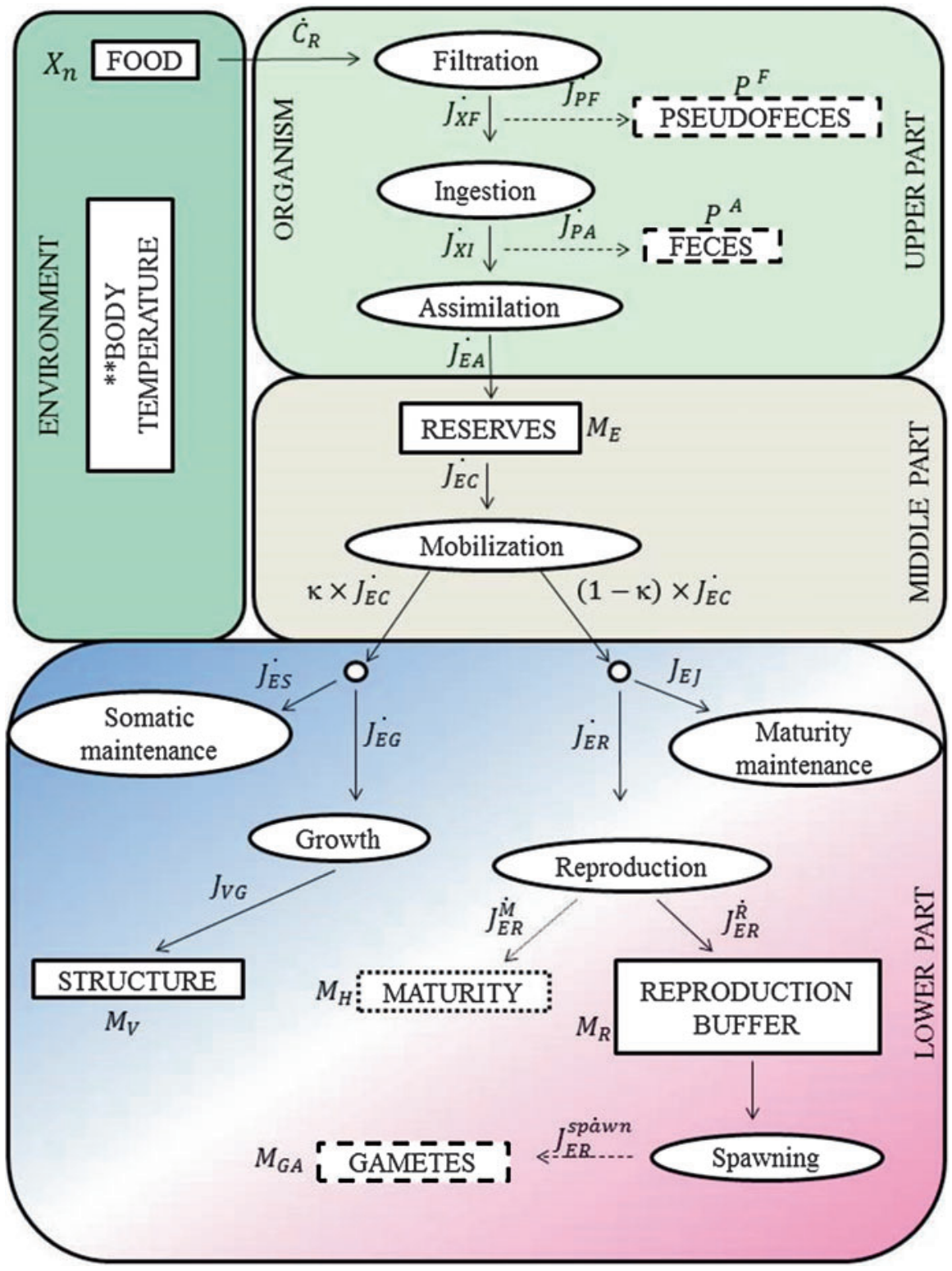

Fig. 3 Schematic representation of the standard dynamic energy budget model (Kooijman 2010) and the flux of energy through an organism, coming from the environment. Apart from food, another important constraint in the metabolic process is individual body temperature. Many suspension feeders, being ectotherms, can have their body temperature approximated as that of the environment, although this is not the case for intertidal invertebrates. This DEB model diagram uses suspension feeders (bivalves) as an example (Copyright release pending) 
particles are selected: a fraction $\left(\mathrm{J}_{\mathrm{PF}}\right)$ will be rejected as pseudofeces, the rest are transported to the mouth to be ingested $\left(\mathrm{J}_{\mathrm{XF}}\right)$ : The ingestion rate $\left(\mathrm{J}_{\mathrm{X}}\right)$.is defined as the passage of food to the gut and depends on food availability, body size, and temperature; according to DEB theory, its formulation follows the Holling type II functional response. The saturation coefficient $\left(\mathrm{X}_{\mathrm{k}}\right)$ depends on food quality (e.g., the ratio between carbon and nitrogen in the organic matter composing food; sensu Pusceddu et al. 2003) and, for example, in suspension feeders it can be expressed by the concentration of chlorophyll-a ( $\mu$ g CHL-a ${ }^{-1}$; Sarà et al. 2012) or amount of carbohydrates, proteins, and lipids (Pusceddu et al. 2003), at which the value of ingestion rate is equal to the half of the maximum. In suspension feeders, the maximum ingestion rate $\mathrm{X}_{\mathrm{k}}$ can be derived from ingestion rate measurements $\left(I R, \mu \mathrm{g}^{-1} \mathrm{~h}^{-1}\right)$ based on typical clearance rate experiments (Sarà et al. 2013a). It should also be noted that the concentration of chlorophyll a can be used to predict food availability on average, though there will be times when chlorophyll a is high but the potential food species are of low quality or contain toxins (i.e., food availability is actually low). Ideally we would have a separate correlation for each time period or combination of potential prey species.

Since both filtration and ingestion in bivalves occur simultaneously, the ingestion rate is equal to the filtration rate. Not all energy coming from the ingestion process $\left(\mathrm{J}_{\mathrm{XI}}\right)$ is digested; differences in the chemical composition between bivalve reserve tissue and ingested food determine energy loss $\left(\mathrm{J}_{\mathrm{PA}}\right)$ as feces. Assimilation rate $\left(\mathrm{p}_{\mathrm{A}}\right)$ is the final step of food processing and is defined as the process where food is converted into the organism's reserves (Kooijman 2010). The rate of assimilated energy is assumed to be independent of the feeding rate per se but is explicitly related to food density through a functional response curve $\left(\mathrm{p}_{\mathrm{Am}}^{*}\right)$ is the maximum assimilation rate per unit surface area and describes the efficiency with which energy is converted into the organism's reserve.

\subsection{DEB Model: The Middle Part}

Reserves represent the core of DEB theory and one of the most important advances compared to classical energy budget models; reserves collect all the energy coming from the environment minus that lost during the feeding process (Fig. 3). An important assumption of the DEB model is that neither the feeding process nor reserves accrue maintenance costs. In the model, the rate at which this energy is used from the reserve follows the k-rule which asserts that a fixed fraction $\kappa$ of assimilated energy is allocated to maintenance and somatic growth, and that the remaining fraction 1-k is available for maturity maintenance and reproduction.

\subsection{DEB Model: The Lower Part}

The lower portion of the DEB comprises all processes that require energy expenditure, i.e., maintenance of the biomass (metabolism), development, growth, and 
reproduction (Fig. 3). DEB theory stipulates that somatic maintenance has priority over growth and that an organism is able to use the reproduction buffer (and in extreme cases the structures) to cope with maintenance costs during starvation periods. Somatic maintenance involves all processes needed by an organism to simply survive (i.e., ignoring growth and reproduction); in ectotherms, generally, maintenance cost scales with volume (of structure, body mass). The parameter $\left[\mathrm{p}_{\mathrm{A}}{ }_{\mathrm{A}}\right]$ is a good approximation of the organism's basal metabolism and is indirectly related to the measurements of oxygen consumption (e.g., Sarà et al. 2013a). Growth is considered as the increase in organismal body mass; the model is based on the growth of an organism under constant conditions and the growth rate in the DEB context reduces to the Von Bertalanffy equation with three parameters (time at length zero, growth rate constant, and maximum size). Growth ceases when all reserves, not used for reproduction, are required for somatic maintenance.

Apart from structural biomass and reserves, two other important variables characterizing the organism are maturity level, $\mathrm{M}_{\mathrm{H}}$, and the reproduction buffer, both of which also need energy to be maintained. Before an organism is able to produce gametes, a maturation level must be reached. The standard DEB model assumes that energy is allocated to the maturity buffer during the individual's juvenile stage. Once the maturity level $\left(\mathrm{M}_{\mathrm{H}}\right)$ is reached, the organism become an adult, and a fixed fraction is continually transferred from the reserve to the reproduction buffer (after accounting for maturity maintenance) and then to gametes production and spawning. The resulting flux of energy moving into the reproduction buffer is defined as the difference between the energy mobilized from reserves and the costs related to the reaching and maintaining of maturity. The real amount of energy stored in reserves $\left[\mathrm{E}_{\mathrm{m}}\right]$ and that available for reproduction and growth $\left[\mathrm{E}_{\mathrm{G}}\right]$ cannot be estimated directly, but it is possible to derive them from somatic maintenance $\left(\mathrm{J}_{\mathrm{ES}}\right)$ and, specifically, the related parameter $\left(\mathrm{p}_{\mathrm{M}}\right)$. If seasonal patterns are known, these parameters can be estimated from energy content before and after the growing season.

\subsection{How to Account the Role of Temperature?}

The flux of energy inside an organism varies according to its own metabolism and thus depends on physiological rates. Since all physiological rates are strictly dependent on body temperature, it represents an important constraint in the DEB theory. To include the effect of temperature within a species-specific range, the relationship originally proposed by S. Arrhenius usually fits quite well (in Kooijman 2010):

$$
\dot{\mathrm{k}}_{(\mathrm{T})}=\dot{\mathrm{k}} \times \exp \left\{\mathrm{T}_{\mathrm{A}} / \mathrm{T}_{1}-\mathrm{T}_{\mathrm{A}} / \mathrm{T}\right\}
$$

where $\mathrm{k}_{(\mathrm{T})}$ is a physiological rate at the ambient temperature $\mathrm{T}$, with $\mathrm{T}$ the absolute temperature (in Kelvin), and. $\mathrm{k}_{1}$ the physiological rate at the reference temperature $T_{1} . T_{A}$ is the Arrhenius temperature. The estimates of Arrhenius temperature $\left(T_{A}\right)$ and of the lower and upper boundaries of the tolerance range can be extrapolated 
from literature data or estimated by a direct calculation of physiological rate at different temperatures. Activities such as locomotion, pumping, ciliary transport, polyp expansion, gut passage, and ingestion are also affected by temperature (e.g., Sanford 2002) which thus affects the intake parameters of the model as well as the energetic cost of each activity.

\subsection{The Main Model Outputs}

The mechanistic nature of the standard DEB model allows the bioenergetics features of an organism to be related to environmental conditions, so that ultimately fitness can be predicted. This is only feasible if the organismal body temperature and concentration of food in the habitat are known, and that all DEB parameters of the species are accurately estimated based on available information. The present versions of the DEB model allows us to quantify the (i) Maximal habitat individual size (MHIS); (ii) the Maturation time (MT) as the time in days to reach the minimal size that allows gamete development and maturation. MT is strictly habitat-specific (i.e., thermal conditions and available food density matter); (iii) the Number of reproductive events per life span (RE) strictly related to the environmental conditions, as the energy that replenishes the reproduction buffer depends on food availability. Furthermore, the standard DEB model assumes that the organism does not spawn until the temperature is above a threshold; this also means that temperature represents a constraint for the occurrence of RE; (iv) the Total reproductive output (TRO) is the total number of eggs per life span. When the energy of a reproductive buffer reaches a threshold, it is packaged into gametes, which are produced in a discrete number of spawning events. Since DEB assumes that the energy needed to build one gamete is usually constant (approximately $0.0019 \mathrm{~J}$ for one egg for bivalves) and that the amount is species-specific, TRO will depend on the amount of energy available for reproduction coming from reserves and stored into a reproduction buffer.

\section{Detailed Examples of Energetics for Suspension Feeders}

So far, we have provided an overview of particle capture, energetics, and energy allocation in benthic suspension feeders. In this chapter, it is impossible to go into great detail for all such groups, and thus we have chosen to discuss three groups that have been the focus of recent research efforts, including those of the authors.

\subsection{Cnidaria}

\subsubsection{Energy Intake}

Cnidaria comprise one of the largest and most important groups of suspension feeders in hard substratum marine habitats. Most cnidarians capture zooplankton 
by passive means, although a few are known to specialize on phytoplankton and bacteria or to capture suspended and sedimenting detrital particles (Houlbrèque and Ferrier-Pagès 2009, review). The feeding structures are tentacles, ranging from less than a millimeter in length to over $10 \mathrm{~cm}$ for benthic forms and much longer for planktonic ones. Ciliary tracts and mucus capture are also utilized by many cnidarians, especially for smaller particles, though mucus strands also function well to capture certain types of zooplankton. Once zooplankton contact tentacles, they are retained by nematocysts and are transferred to the pharynx area where ingestion occurs. Digestion happens in the coelenteron cavity, and particle ingestion can occur anywhere on the interior surface. Anthozoans have specialized structures (mesenteric filaments) that wrap around prey and form a temporary digestive space where enzymes can be concentrated and phagocytosis of partially digested prey occurs. The entire tentacle and oral disk surface areas can be involved in particle interception and capture, and in some colonial forms, the tissue between polyps can be involved as well.

For most sessile cnidarians, tentacles are oriented to intercept flow maximally and thus to maximize particle contact. This is also true for whole colonies, such as gorgonians, which orient the broad axis to flow even though this orientation greatly increases drag and can result in colony mortality during storms (Sebens 1997). Clearly, the benefits of high particle and light capture outweigh the high risk incurred for those infrequent storm events that are severe enough to dislodge entire colonies. Sea anemones display a wide range of tentacle morphologies from elongate thick tentacles capable of capturing large zooplankton and benthic mobile creatures to complex crowns of very small tentacles that can capture only the smaller zooplankton but which maximize surface area for particle interception. In all cases, particle interception depends on the cross-sectional surface area presented to flow, and the efficiency of capture for each range of particle size and type will be affected by tentacle and colony morphology. Corals have the same broad range of tentacle types and also greatly increase surface area by having branching or upright plating growth forms. Octocorals have less variability in tentacle form; their eight tentacles per polyp are generally small and have even smaller side branches (pinnules) that increase surface area and probably aid in capture of particles in the size range of phytoplankton to very small zooplankton (Sebens and Koehl 1984; Fabricius et al. 1998; Coma et al. 1994, 1998). Hydroids also utilize very small tentacles, but without the side branches, and seem best adapted to capture individual small to medium size zooplankton (Sebens 1987a, review).

Benthic cnidarians present a capture surface to moving water; this can be a whole colony surface (gorgonians, hydroids) or a tentacular area (anemones, corals, zoanthids) and thus we expect prey capture to be related to some aspect of surface area (e.g., a power function with 0.67 exponent). When colonies grow as thin sheets, or branches with similar repeated units, metabolism can scale linearly with mass. Energy intake, from prey particles, can also scale linearly with mass in this case since production of more polyps of the same size and shape results in more feeding surface. However, even among colonial forms, polyp size ranges over several orders of magnitude. Energy intake thus depends on tentacle size, shape, and surface area as 
well as on the size range of particles available and efficiency of capture for any cnidarian species. Capture rates are also modified by flow speed, which varies widely on all scales of habitat and over time. For these reasons, it is quite difficult to measure food availability in the environment and to use that information to model ingestion.

Corals capture a wide range of particle sizes and types; although zooplankton are the most important prey for many corals, others utilize organic material in suspended or depositing sediments as a source of nutrients and energy (Mills and Sebens 2005; Anthony and Fabricius 2000; Houlbrèque and Ferrier-Pagès 2009, review). Plating corals in deep reef habitats may be able to intercept a rain of sedimenting particles coming from the shallow reef habitats, including fish fecal material produced in copious amounts on reefs. Corals that can utilize suspended detrital material may be able to live in habitats that would be impossible for zooplankton specialists. In fact, sedimenting material was first studied as a stressor for corals, and it can be energetically expensive to remove for species that cannot make use of it. Anthony and Fabricius (2000) demonstrated marked differences in energy balance for corals living in Australian reef areas with high turbidity, with some corals much better able to utilize suspended organic material. Some tropical octocorals with symbiotic algae also feed on a range of small zooplankton, microzooplankton, diatoms and dinoflagellates (Ribes et al. 1998).

\subsubsection{Energetic Costs}

Benthic cnidarians are passive suspension feeders and do not have to effect much movement to capture their prey. They do move to expand and contract and probably have to have some water flow into their coelenteron to maintain their expanded condition via their hydrostatic skeleton. Medusoid forms, of course, swim continuously and use the swimming process to generate feeding currents. Cnidarians are metabolic conformers, so their oxygen consumption declines when the surrounding oxygen concentration is low. Metabolic cost scales as a higher power of mass than does energy intake, often between 0.75 and 1.0 depending on the exposure of tissues to water with high dissolved oxygen concentrations. If there are parts of an individual or colony that are far from the ambient water, and thus exposed to less oxygen, the metabolic rate is likely to scale as a power of mass less than 1 . Some species can also produce low tissue oxygen conditions internally by contracting polyps and reducing the surface area in contact with the overlying water (Sebens 1987a, review). This can be a mechanism of conserving energy when conditions for prey capture are poor, as occurs in sea anemones, or during intertidal exposure when they probably cannot feed.

Coral growth is most prolific in shallow wave-impacted reef zones, and coral growth rate generally increases with flow at least for the lower range of flows measured on reefs (Sebens et al. 2003). The optimal flow conditions for any coral species thus depend on this balance of increased cost and increased intake with flow. It is also quite clear that water movement across tissue surfaces increases metabolic rate (Sebens et al. 2003) and that oxygen concentrations near coral tissues can be 
reduced to near zero at night in low flow conditions. Water flow changes the boundary layer profile, such that diffusion of oxygen to tissues becomes much more rapid under high and turbulent flow conditions (Denny 1988). Very slow flow produces a thick boundary layer that hinders diffusion of oxygen from overlying water, resulting in depletion near tissues. On the other hand, endosymbiont photosynthesis creates extremely high oxygen concentrations in tissues that can be damaging to cells, resulting in production of compounds that protect the cells from free radicals of oxygen. Removal of excess oxygen from tissues is also enhanced by water movement, and particle capture increases with flow at least in the lower range of flows (Sebens et al. 1996a, b, 1998). A few sessile anthozoans display a rhythmic pumping action of their tentacle crown, which may serve to break up the diffusive boundary layer and thus enhance both gas and nutrient mass transfer (e.g., octocorals). Another possible mechanism to disrupt the diffusive boundary layer is by ciliary activity; many corals have ciliated tracts on their surfaces that move mucus and food particles and which could also modify the water layer closest to tissue surfaces.

Energy budgets will thus change markedly with flow regime; corals living in a low flow and low light environment, such as in deeper reef habitats, face the greatest limitations. Although metabolic costs may be reduced under such conditions, both photosynthesis and particle capture will also be low. More water movement also increases photosynthesis in some coral species (Patterson et al. 1991), so corals in low flow habitats may have less energy to offset costs. In addition to toxic effects, high tissue concentrations of oxygen result in high rates of respiration during the day, which can be measured experimentally by darkening corals momentarily after high light exposure. The elevated metabolic rates during daylight hours represent a high cost to corals, but that high cost may be easily met by photosynthate production. In addition, high metabolic rates may also reflect greater rates of ion pumping for calcification, nutrient active uptake, or other metabolically expensive activities.

Stressful environmental conditions have the potential to increase metabolic costs for corals; examples of such stressors include increased sedimentation, high or low temperatures, and more acidic seawater conditions. Corals which have lost all or most of their zooxanthellae after a bleaching event have a lower metabolic rate because there is less tissue per unit area, which may help them survive the following months and potentially recover. Availability of prey, lipid storage before bleaching, and severity of bleaching can all affect the energy balance of affected corals and are important factors determining their probability of mortality. Corals facing more acidic seawater conditions, on the other hand, may have metabolic rates continually elevated to maintain calcification; this may be less of a problem in tropical high light habitats but could be a substantial additional cost in temperate and tropical low light habitats where there is no excess of photosynthate production (see chapter " $>$ The Limits of Photoadaptation and Photoacclimation in Symbiotic Corals", this volume). Additional prey availability can offset the higher costs of calcifying in more acidic conditions, but acidification has been shown to reduce feeding rates for at least one species (Houlbrèque et al. 2015). 


\subsubsection{Symbiosis with Primary Producers}

Cnidarians of many types rely at least partially on photosynthetic endosymbionts to meet their energy needs. Hydroids, scyphozoans, and many anthozoans harbor zooxanthellae (symbiotic dinoflagellates) in their gastrodermal cells and others harbor zoochlorellae (symbiotic chlorophytes). In high light habitats, such symbionts can provide more energy than needed to meet daily metabolic requirements, and there may even be a loss of excess photosynthate to the surrounding water (Sebens 1987a, review). Having algal symbionts also helps facilitate calcification in corals, which is especially important under conditions of low aragonite saturation state (low $\mathrm{pH}$, high pCO2). Energy produced by symbionts can be used to pump hydrogen ions across cell membranes adjacent to the calcifying space, reducing their concentration at the site of calcification. Energy derived from heterotrophy can also assist calcification (Ferrier-Pagès et al. 2003) and may thus allow corals to grow and build skeleton in conditions that are less optimal for calcification.

Despite being so advantageous to the energy budget, symbiont photosynthesis alone cannot provide the nutrients necessary for tissue growth and production of reproductive organs and gametes. In most cnidarians, those nutrients are garnered by prey capture. Yet, there are some cnidarian groups that appear to have very reduced digestive apparatus and are not known to ingest prey; in such cases, uptake of inorganic nutrients directly from seawater could be the source of other limiting nutrients (Sebens 1987a, review). This also appears to be true for mollusks, such as the tropical giant clams, that rely on zooxanthellae for their energy. Energy from photosynthate can be used to fuel active uptake of dissolved inorganic nutrients from seawater, and thus can indirectly assist with tissue growth.

There is also evidence suggesting that tissue growth and skeletal growth in corals are somewhat decoupled and that tissue thickness can serve a storage function. When prey are plentiful, but conditions may not be ideal for calcification, tissue growth can be rapid and the amount of protein per unit skeletal area can increase many fold (Ferrier-Pagès et al. 2003). On the other hand, when corals are stressed, such as after bleaching events, tissue thins substantially and protein per unit surface area can be reduced to less than a tenth of the maximum. This pattern may be adaptive in several ways; first, when conditions are good for tissue growth, the additional tissue per unit area accumulates but is later spread out as new skeleton is produced, even if prey are less abundant then. In poor conditions, the coral maintains its surface area for prey capture and nutrient uptake even when the tissue becomes very thin. Thus, the feeding surface area to biomass ratio is much higher with very thin tissue, and recovery will be assisted.

It has long been recognized that many corals depend on both photosynthesis and prey capture for their energetic needs, yet the question of how much energy they get from each source has been problematic. It is easier to measure the response of photosynthesis to light (P/I curve) and to determine the production of energycontaining carbon compounds based on net oxygen production during experiments. The contribution of zooxanthellae to coral (animal) respiration (CZAR) (Sebens 1987a; Houlbrèque and Ferrier-Pagès 2009 reviews) was an early attempt to quantify how much energy corals were getting from their symbionts, usually in short-term 
studies. It quickly became evident that shallow water coral species often had photosynthetic production that greatly exceeded the respiratory needs of the coral, whereas those from deeper reef habitats were generally not meeting those needs from photosynthesis, though it could still represent a large fraction of energy intake.

If shallow water corals were producing more than the coral needed, what happens to that photosynthate? First, energy needs and carbon needs are not the same. Carbon is needed to build molecules (anabolism) and to replace those that are broken down for precursors or for energy (catabolism) or are lost to the environment. When new tissue is produced, including gametes and reproductive organs, or when damaged tissue is replaced, carbon and energy are both needed. There is also substantial loss of carbon and energy in mucus production, nematocyst production, and other losses to the environment. So, CZAR has to be well over $100 \%$ to meet the needs of a coral for respiration, growth, reproduction, and replacement of lost tissues and compounds. Basal metabolism is usually the largest energetic cost in any time period, but it is not the only one. The algal symbionts are also respiring, reproducing, and replacing structures and whole cells. A CZCR might be more informative, defined as the contribution of zooxanthellae to coral (animal and symbiont) respiration.

On the other side of the balance, we can compare CZAR to a similar contribution from heterotrophy, termed CHAR. Again, this has been done for the short term and for experimental situations (Houlbrèque and Ferrier-Pagès 2009, review). Certainly there are coral species that do not have zooxanthellae or other photosynthetic symbionts, and such species must be getting all of their energy needs from plankton and particle capture or dissolved compounds, so we might expect this heterotrophic contribution to be substantial even for species that have symbionts, which it is.

Photosynthesis by symbionts is less effective in temperate zone cnidarians than for those in tropical habitats, due to colder temperatures and less irradiance seasonally. Nonetheless, both zooxanthellae and zoochlorellae symbionts are present in some species, such as the very well-studied Anthopleura elegantissima on the west coast of North America (Bingham et al. 2014). This species can be found naturally without photosynthetic symbionts, in caves and other low-light situations, where populations are generally not as dense as in the nearby high-light situations. Low intertidal populations in well-lit areas generally have large clonal aggregations, with large polyps and high biomass. Polyps capture both benthic and planktonic prey and can obviously persist on this resource alone in some habitats; the symbionts, however, provide enough additional energy that clones of symbiotic anemones would likely outcompete clones of asymbiotic anemones in the well-lit habitats (Bingham et al. 2014).

\subsubsection{The Size of Feeding Units}

Cnidarian polyps come in a wide range of sizes, from hydroids less than a millimeter to sea anemones nearly a meter in diameter (Sebens 1987a). Tentacle sizes also vary considerably, and tentacles of octocorals are furnished with side branches that make them very effective for capture of smaller particles (Sebens and Koehl 1984). The great advantage that accrues to small polyps in a cnidarian colony is the increased feeding surface area per unit mass and the fact that both feeding surface and 

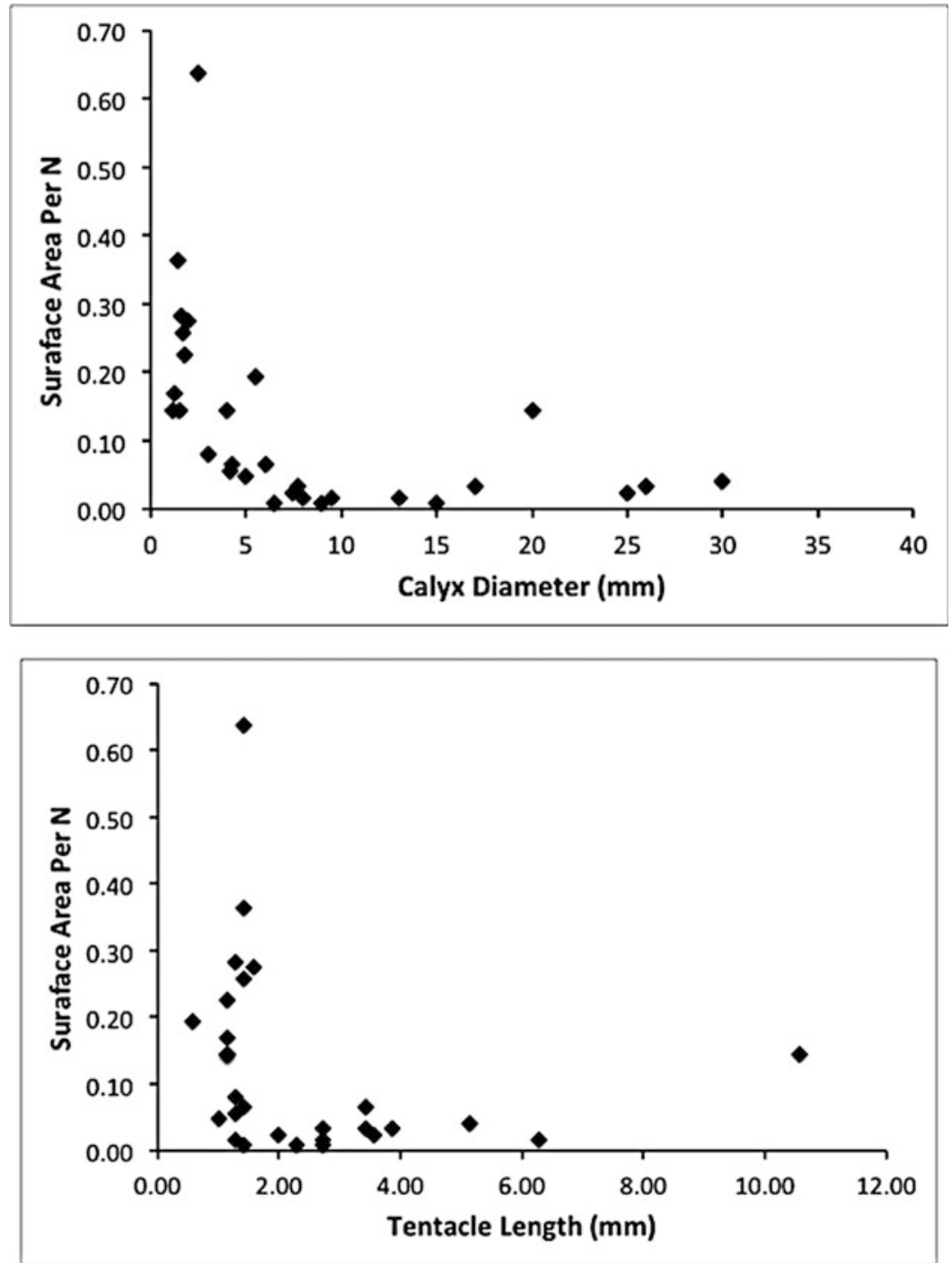

Fig. 4 Polyp sizes of Caribbean corals, surface to biomass ratios. Top: surface area per unit tissue nitrogen (biomass proxy) $\left(\mathrm{mm}^{2} / \mathrm{ug} \mathrm{N}\right)$ plotted versus coral calyx diameter (polyp size proxy). Bottom: surface area per unit tissue nitrogen (biomass proxy) $\left(\mathrm{mm}^{2} / \mathrm{ug} \mathrm{N}\right)$ plotted versus coral tentacle length. Species of each coral by calyx size are given in Sebens 1997 (Replotted from data in Sebens 1997)

metabolic cost scale linearly with mass (Sebens 1979), and thus colony mass can theoretically continue to increase without a loss of energy surplus per unit mass. However, there are also advantages to larger polyp size, which are primarily the ability to capture larger prey, and increased competitive ability (Sebens 1997; Lang 
and Chornesky 1990). Sebens (1997) examined the size of polyps for Caribbean scleractinian corals and found that most species had relatively small polyps and high surface to mass ratios (Fig. 4). Sebens et al. (1998) also found that corals with both small and medium sized polyps captured prey of about the same size range, though later work with some of the largest coral polyps showed that they do in fact capture larger prey (unpublished data), which is also true for sea anemones (Sebens 1987a).

An important trade-off is apparent when optimum polyp size within a colony or dispersed clone is considered. Clearly, if energy intake scales at a lower power of mass than energetic cost, smaller units are better. Although there is one predicted size optimum for a single individual, there is no such optimum for splitting up a given mass of tissue into a number of units, such as polyps. The same energetics model applied to this case predicts that polyps should be infinitely small (Sebens 1979). Dividing any mass into two units produces a situation where the ratio of feeding surface to mass increases and this just gets better the more units the mass is split into. Even among a defined group such as reef corals, most species in a reef or region have small polyps a few $\mathrm{mm}$ in diameter, while a few have larger polyps up to centimeters in diameter. For those corals that depend primarily on light capture (very small particles indeed), energetics models predict that polyps should be as small as possible and still be able to carry out all necessary functions, including reproduction (Sebens 1979). Hydroids form colonies of even smaller polyps from less than a mm to over a centimeter in polyp diameter. So, if the energetic considerations predict the tiniest polyps possible, why are all polyps not the same small size?

Sebens (1979) considered one possible explanation; given a normal distribution of prey biomass (in the energetics model) where polyps can consume prey whose length is about the same as polyp diameter (realistic, based on field data), polyps that are too small to capture much of the prey size spectrum are at a disadvantage. A new optimum size is predicted for polyps within a colony; polyps must be large enough to capture most of the prey sizes available, but small enough to take advantage of the high surface to mass effect. This optimum is just above the mean length of prey in this example. At this optimum, polyps sacrifice some prey capture (larger prey sizes) for the benefit of greater capture area. This result still predicts that all colonies would have small polyps, just not infinitely small. If most colonies have small polyps and specialize on the most abundant prey by biomass (small to medium sizes), that leaves an opportunity for other species to specialize on large prey. For these species, the availability spectrum is different because they have better ways to handle large prey but may then be less efficient at handling small prey.

Another possible reason for having large polyps is direct competition with other corals (Lang and Chornesky 1990). Sebens (1997) noted that corals with large polyps are positioned higher in the competitive hierarchy based on mesenteric filament egestion and use of sweeper tentacles. Corals with small polyps are generally fast growing species that can overtop or shade other corals, but corals with larger polyps can prevent this overgrowth by digesting or damaging the faster growing (small polyp) species. Enhancing feeding surface area by forming upright branches, with high colony (skeletal) surface area to volume or mass, is another way to improve the energy intake situation. 
Tall branching or plating corals, usually with small polyps, are also more susceptible to damage or removal in severe storms, whereas encrusting or massive mounding colonies, usually with larger polyps, survive these events. Thus, it may be equally advantageous, in fitness terms, to be an energy optimizer with small polyps or to be a survival maximizer with larger polyps. Coral species could thus coexist on the same reef by being part of a fugitive-dominant process, where some species are good colonizers and fast growers, and others are better long-term competitors and survivors. Disturbance, from severe storms or predator outbreaks (e.g., Acanthaster, crown-of-thorns seastar), provides open space that can be colonized and, within a given reef zone, certain coral will be competitive dominant and eventually outcompete the early colonists. Given that such disturbances probably occur on a multi-decadal scale, space could be opened up frequently enough to allow the fugitive species (also energy maximizers) to persist permanently on any reef.

\subsection{Bivalve Mollusks}

Bivalves belong to a large class of mollusks and penetrate habitats from subtidal (e.g., sediments hundreds of meters deep) to intertidal (e.g., tide pools). Bivalves are ecosystem engineers worldwide; by means of their shells they introduce complexity and heterogeneity into benthic environments and are important elements of habitat structure affecting population, community, and ecosystem-level processes.

\subsubsection{Energy Intake}

Bivalves are the masters of the strategy (from an evolutionary point of view) of "sit and wait" to obtain food. As mostly sessile suspension feeders when adults, they have evolved an efficient filtration apparatus allowing them to remove microscopic particles (from bacteria $[\sim 1 \mu \mathrm{m}]$ to detritus and zooplankton [hundreds of $\mu \mathrm{m}]$ ) of different nature that are selected first on the basis of size and later for quality. The size of particles maximizing ingestion rate is species-specific and is centered in a range of only few microns (e.g., Mytilus has maximum ingestion for the particle size range of 1 to $10 \mu \mathrm{m})$. Bivalves are essentially opportunistic organisms, relying on those organic particles falling in the optimal size range that are available in the water column and which enter their feeding apparatus by inhalant water flow. Indeed, to assure a sufficient amount of energy to support survival, somatic maintenance, growth, and reproduction, these animals need to pump and process very large amount of waters through the filtration system.

Bivalves employ a hydromechanical and mucociliary mechanism of particle transport. The process of filtering in bivalves is based on the action of three types of cilia on the gill filaments. Lateral cilia move entering water by beating in metachronal waves allowing for constant water movement. Thus, water flows through gills, and particles are retained by laterofrontal cirri in a number of ways; particles may be sieved, intercepted, or may impact on gill filaments by inertia, motile particle motion, or deposition by gravity. While trapping by sieving is not strictly dependent on size of spaces between cirri, all other mechanisms depend on 
it. Also, particles are then transported at the level of frontal cilia by mucus trains or strings to labial palps and mouth. There are some deviations to this scheme of filtering, such as those occurring in scallops and oysters. However, when particles approach at the level of labial palps, a sorting action happens; particles here can be (i) transported to the mouth to be ingested or (ii) ejected through pseudofeces. Pseudofeces production represents a sort of compensatory process allowing bivalves to maintain food uptake at a high level, in spite of dilution of the food items with indigestible material, thereby increasing the total amount of organic material ingested per unit time.

There has been much controversy over the last decades as to whether there are well specified and evolved preingestive selection processes in bivalves as a function of particle quality or quantity. In general, most bivalves living under conditions of dense particulate mixtures (inorganic and organic) as in shallow waters wrap certain particles in mucus (secreted by the epithelia of the pallial organs) and then reject them through pseudofeces. Thus, those extra particles are expelled from the organisms without passing through their digestive tract. Being mucus compounds are highly labile, composed of mucopolysaccharides associated with particle processing, pseudofeces locally serve to couple benthic and pelagic habitats supplementing the flow of suspended particles falling from upper layers of the water column to benthic habitats.

\subsubsection{Energetics Costs and Energy Budget}

Bivalves are physio-energetically complicated animals despite their apparent simplicity! All have carbonate shells that, in the context of ocean acidification, will dissolve under certain conditions. Some are intertidal, and severe storms may stochastically influence their survival and thus their vertical position; they can counteract this by producing cement or byssus for stronger attachment. All bivalves need to produce endogenous mucus to assist food particle transport and wrapping of pseudofeces. All such factors affect energetic performances of individuals, with both direct and indirect effects at the population level (e.g., Carrington et al. 2015), and all are usually acting on different components of the energy budget. The influential assertion by Conover that a "bivalve's life is spent in a nutritionally dilute environment" is certainly valid for all bivalves. The amount of energy spent to gain food through filtration is based on low-energy pumps that continuously move the surrounding water through the gills. Feeding costs are proportional to feeding rate and are accounted for in DEB models by a reduction of energy gain per food unit (Kooijman 2010). In general, feeding costs per unit of food should increase with decreasing food density because of the increased effort of extracting food from the environment (they filter more when food is diluted in a matrix of inorganic particles such as silt).

Several studies have inferred high energy losses of several types, in a wide array of species. In Mytilus edulis and M. californianus, they were estimated at more than $20 \%$ of the ingested ration of algal cells. Mucus is an important element in suspension feeding (particle adhesion, movement, and pseudofeces wrapping), but there are not sufficient data on the energetic cost of its production. The cost is 
unlikely to be high since mucus produced in feeding is either reabsorbed or ingested, and the animal is generally in adequate energy balance to support the costs of mucus produced for rejection. In contrast, most intertidal bivalves could not feed if they do not remain fixed on substrata. To reduce the likelihood of dislodgment, they need to spend energy to produce byssus. This involves energetic costs and in current energetic theories (for example DEB) the energy to synthesize all somatic structures involved in survival (e.g., byssus and shells) are usually paid from the energy component used for somatic metabolic maintenance (Kooijman 2010). For byssus production, there are estimates of about $15-18 \%$ of the somatic maintenance component of the energy budget. Theoretical simulations have showed that decreasing byssus production can impair the ability of individuals to persist over time (Carrington et al. 2015), whereas increasing byssus production results in lower growth and reproduction. Fitness is maximized at some intermediate allocation of energy to byssus production.

Once food compounds are assimilated, according to current bioenergetic theory, they accumulate into reserves and from there energy is constantly allocated to different functions, first somatic and maturity maintenance and then the amount remaining (if any) is used for growth and reproduction. We can estimate the amount of energy spent for maintenance (i.e., the cost of processes needed by the organisms to survive, including all the biochemical processes necessary for basal metabolism particularly costly protein synthesis/turn over; only indirectly through oxygen consumption experiments (Kooijman 2010; Sarà et al. 2013a, b)). However, oxygen consumption can also include the cost of feeding, digestion, and growth/synthesis. Maintenance costs can vary from 10 to $15 \mathrm{~J} \mathrm{~cm}^{-3}$ for some small mussels such as Brachidontes pharaonis, oysters such as Crassosterea gigas, and cockles such as Cerastoderma edule to over $30-60 \mathrm{~J} \mathrm{~cm}^{-3}$ for clams such as Macoma baltica and Perna sp. (Matzelle et al. 2014).

The large differences among cost estimates depend on whether byssus production is a part of metabolic cost, and whether cost is a function of habitat (intertidal, subtidal, etc.) or of maximum size, etc. (Kooijman 2010). Costs of structure (tissue needed to grow) in bivalves are high in energetic terms. The amount of reserve energy required to synthesize a unit volume of structure includes the energy stored in that tissue as well as the overhead costs for anabolism during its production. These values range from about 2,000-3,000 $\mathrm{J} \mathrm{cm}^{-3}$ for clams, cockles, and oysters up to about 4,500-5,000 J cm$~^{-3}$ in mussels (M. edulis, Matzelle et al. 2014). Such large variation in components of the energy budget lead to the concept that (as for all animals) every extra energetic cost spent to cope with environmental variability (as expected in a context of climate change) has the potential to impair growth and reproduction and thereby lower the potential persistence of populations over time. Such a result is particularly important in bivalves which are ecosystem engineers, where changes in local density and abundance of these species can affect the whole associated assemblage causing a net biodiversity lost. 

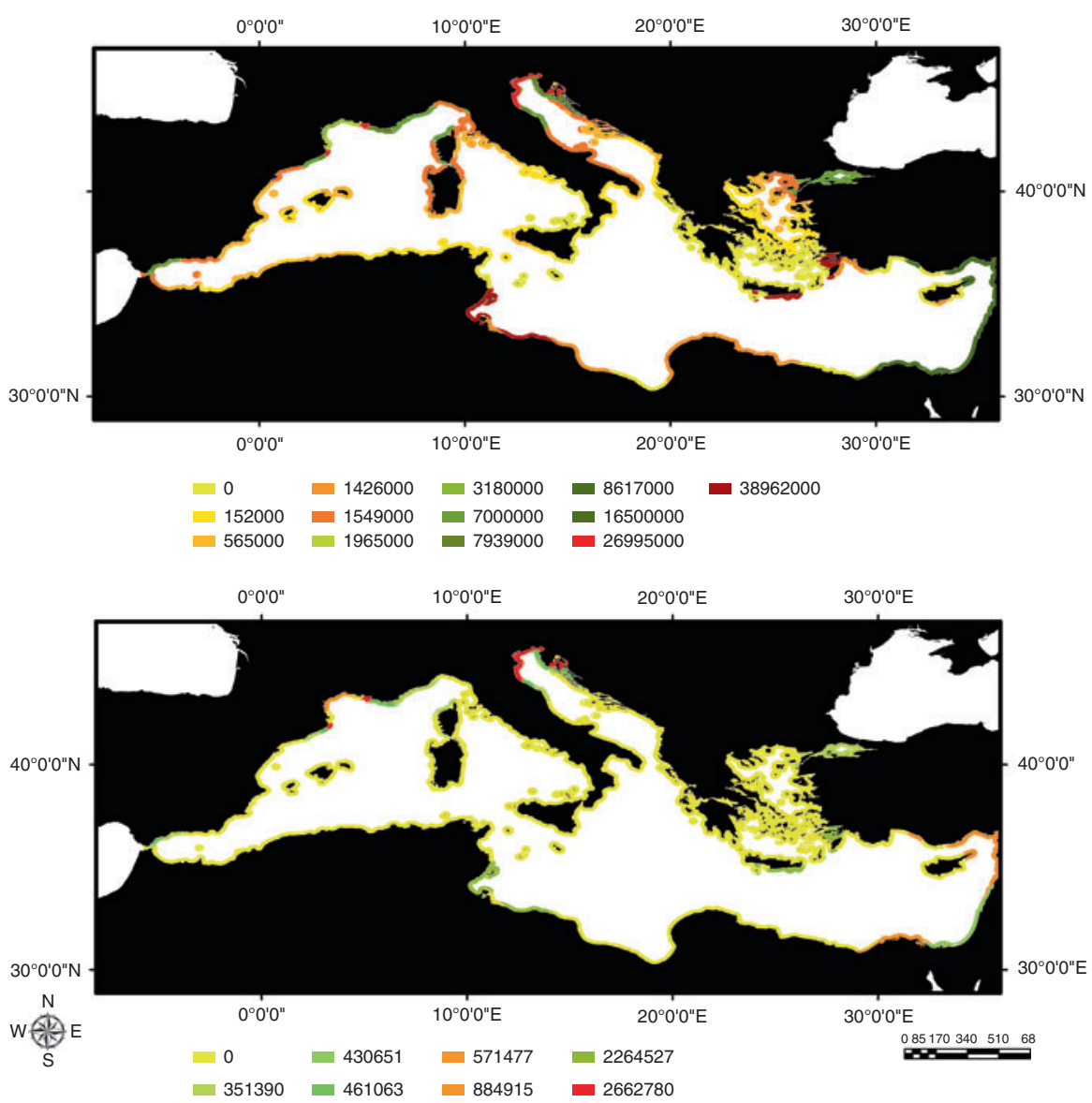

Fig. 5 Mechanistic DEB based prediction for number of eggs of Mytilus galloprovincialis (top panel) in 2020 (A1B scenario; IPCC, 2014) and the number of eggs per lifetime (bottom panel) in 2020 under hypoxia conditions. As shown, such a multiple-stressor condition will lead to a large recession of that species across the whole basin (G. Sarà, unpublished)

\subsubsection{Putting It All Together: An Example Using the DEB Approach in Modeling Mussel Distribution}

Using a fully mechanistic DEB-parameterized example for the Mediterranean blue mussel (Mytilus galloprovincialis) throughout that basin (Fig. 5; Sarà, unpublished), we show how having quantitative information implemented with the mussel's functional traits allows us to study the effect of increasing temperature (in 2020, with and without augmented hypoxia conditions) on the number of eggs produced over a lifetime. In this example, the species can produce eggs at high rates over most of the basin in 2020 with increased temperature, but both range and egg production are much reduced in the case of predicted hypoxic conditions. Outputs of such 
mechanistic models provide several applications for population management enabling managers to support adaptation and mitigation plans for species that are beyond reach of simpler statistical correlative approaches. This quantitative information (e.g., body size and fecundity) along European coasts at any point in time from now to 2050, and beyond whenever possible, will feed into population models for target species with time-steps matching the biology of each species. Most ecological processes are essentially density dependent. Thus, if we are able to quantitatively estimate fecundity, for instance, we have in our hands important information from which to derive the other main components of population dynamics.

\subsection{Cirripede Crustaceans}

Barnacles are found in all of the world's oceans and have persisted through periods of global warming (e.g., Palaeocene-Eocene Thermal Maximum) and cooling (e.g., Pleistocene glaciation). Given their ability to cope with a wide range of environmental conditions (Buckeridge 2012), understanding how barnacles respond to changes in temperature and water flow is an especially important topic in light of potential environmental variation due to climate change and/or species invasion into new habitats (Sanford and Menge 2001).

\subsubsection{Energy Intake}

Barnacles feed on a variety of planktonic food types that range in size from $\mu \mathrm{m}$ to $\mathrm{mm}$. Ultimately, food intake depends on the velocity of the fluid medium carrying food particles, particle concentration, and the capture area presented by feeding appendages. Together, these factors contribute to the total flux of particles past barnacles, which possess an array of morphological and behavioral responses to enhance particle capture. Barnacles capture food with six pairs of biramous feeding appendages, called cirri. Each cirrus is segmented and each segment bears a set of small, hair-like protrusions called setae. The largest cirri form a cirral net, used to capture food particles, which are moved towards the mouth with the aid of the three sets of shorter cirri. Barnacles can actively move the cirral net via a combination of hydrostatic pressure and striated muscle fibers (Neufeld and Rankine 2012). Cirri may be extended for prolonged periods permitting passive capture of suspended particles or they may actively be extended and retracted into the water column (Geierman and Emlet 2009; Trager et al. 1990). Indeed, a range of behaviors have been defined that include: testing, where the aperture of the test opens, but only a single cirrus emerges; pumping, where cirri are extended, but the cirral net remains unfurled; slow, normal, and fast beating, where rhythmic expansion of the cirral net occurs and prolonged extension, where the cirral net is held open (Anderson and Southward 1987; Nishizaki and Carrington 2014a).

Cirral activity may be influenced by a number of environmental factors. For many barnacle species, cirral activity displays a thermal optimum (Anderson and Southward 1987, review). For some species, there is a behavioral switch from active beating at 
low flows to passive extension at higher flows (Trager et al. 1990). Active beating of the cirral net increases particle flux by both increasing the velocity with which fluid passes the cirral net and by creating a feeding vortex that draws food particles towards the cirral net. In oscillating flows, barnacles reorient the cirral net to face the direction of flow and presumably increase particle capture (Trager et al. 1990).

Under low water velocities, barnacles most commonly display beating behaviors that involve fully extended cirri (i.e., slow, normal, and fast beating), whereas at fast flows barnacles adopt abbreviated behaviors (i.e., pumping, testing) (Nishizaki and Carrington 2014a). This suggests that at high velocities barnacles withdraw cirri to prevent physical damage and extend cirri at slow flows to maximum food particle capture. However, barnacles also engage in pumping behavior under conditions of low $\mathrm{O}_{2}$ (e.g., low flow, high temperature), presumably to increase ventilation (Nishizaki and Carrington 2014b). Moreover, cirral behavior likely serves to both maximize food capture and facilitate oxygen exchange (Nishizaki and Carrington 2014a, b).

Particle capture is presumably linked to morphology, specifically the size of the cirral net. Cirral morphology displays flow-induced phenotypic plasticity, with longer cirri for barnacles at low flow and shorter cirri at high flow (Arsenault et al. 2001; Gilman et al. 2013; Nishizaki and Carrington 2014a). This plastic response, however, is generally limited to water velocities $<0.6 \mathrm{~m} \mathrm{~s}^{-1}$ and is absent at faster velocities (e.g., 2.4-14.0 $\mathrm{m} \mathrm{s}^{-1} ; \mathrm{Li}$ and Denny 2004). Barnacles in fast flow retract their cirri, allowing them to avoid damage and such behavior may explain why cirral morphology is invariant at high velocities. At low flows, longer cirri and larger cirral nets may represent a response to maintain high particle capture rates. Barnacles also develop longer cirri at higher temperatures, raising the possibility that cirral length is related to oxygen availability (Nishizaki and Carrington 2015).

The spatial distribution of barnacles (e.g., solitary versus aggregated individuals, density of individuals) may also affect particle capture rates. Barnacles can form elevated hummocks of tall, densely packed individuals, and individuals near the peaks of these hummocks have higher feeding rates compared to solitary individuals or barnacles in the troughs between hummocks (Bertness et al. 1998). This likely permits individuals at the peak to access faster flow speeds, higher particle concentrations, and ultimately flux of food particles. However, hummocks are also at risk of dislodgment by waves and thus risk of mortality may be higher there.

Patterns of particle capture can be predicted by models using the mechanisms of filtration as described above (see Sect. 2.1). Such models suggest that for B. glandula, particle capture by direct interception is between $10^{1}$ and $10^{8}$ times greater than capture by inertial impaction, gravitational deposition, or diffusional deposition (Nishizaki and Carrington 2014a). However, empirical patterns of particle capture across temperature and flow were accurately predicted by such models only when cirral beating behavior was incorporated. This suggests that the limits to feeding success, and thus energy intake, are not simply biophysical but also behavioral in nature. Although cirral activity is often used as a measure of feeding activity, the correlation between activity and gut content is weak. For instance, Nishizaki and Carrington (2014a) report that even with a high percentage of barnacles actively 
beating ( $68 \pm 3 \%)$, a far lower percentage had actually ingested food particles $(22 \pm$ $3 \%$ ). This discrepancy suggests that cirral activity may also serve other functions and that cirral activity alone is a poor proxy for barnacle feeding rate (Nishizaki and Carrington 2014a).

\subsubsection{Energetics Costs}

As sessile ectotherms, barnacles have generally low metabolic rates and energetic costs. Although cirral activity does carry an energetic cost (Gilman et al. 2013), rates of oxygen consumption among different behaviors (e.g., pumping, normal, and fast beating) were found to be equivalent. In laboratory chambers, respiration rate increased with both water temperature and flow speed; flow had less influence on respiration at low temperatures and a greater effect at high temperatures (Nishizaki and Carrington 2014b). Although respiration rates in water are usually higher compared to those in air, long periods of emersion can make aerial respiration a significant energetic cost in their total energy budget during a period when they are not feeding. Molting is considered a minor constituent of the overall energy budget ( $\sim 2 \%$ ), but molting frequency increases with both turbulence and temperature and greater molting frequency is generally associated with more rapid growth.

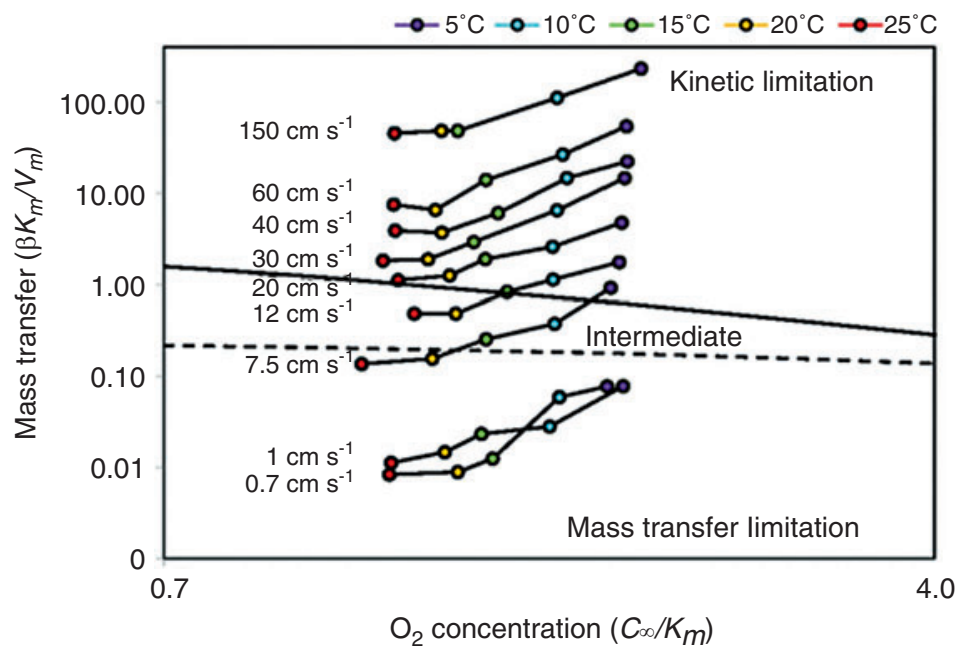

Fig. 6 Nondimensional mass transfer coefficient $\left(\beta K_{\mathrm{m}} / V_{\mathrm{m}}\right)$ plotted against nondimensional oxygen saturation $\left(C_{\infty} / K_{\mathrm{m}}\right)$. Each circle is calculated from means of three trials of the respiration experiment; colors indicate different temperature treatments and each line represents trials conducted under the same water velocity, as indicated on the graph. The solid line represents the upper limit for conditions of mass transfer limitation and the dashed line represents the lower limit for conditions of kinetic limitation. $\beta$ is the mass transfer velocity $\left(\mathrm{m} \mathrm{s}^{-1}\right), V_{\mathrm{m}}$ is the maximum uptake rate $\left(\mu \mathrm{mol} \mathrm{O}_{2}\right.$ $\left.\mathrm{m}^{-2} \mathrm{~h}^{-1}\right), K_{\mathrm{m}}$ is the oxygen concentration at which the uptake rate is one-half of its maximum $(\mu \mathrm{mol}$ $\mathrm{O}_{2} \mathrm{~m}^{-3}$ ), and $C_{\infty}$ is oxygen concentration in the bulk flow (From Nishizaki and Carrington 2015) (Copyright release pending) 

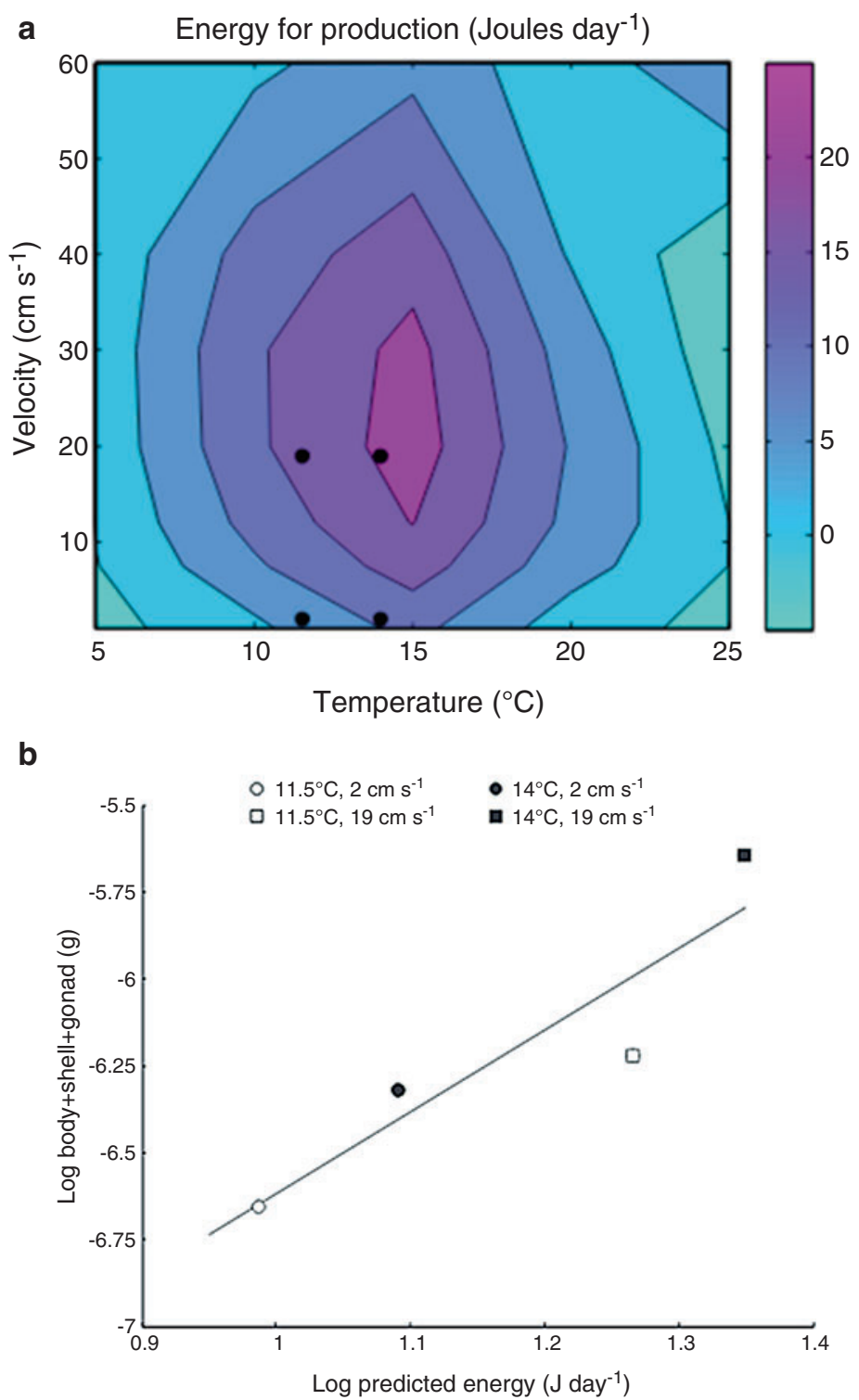

Fig. 7 Model predictions for barnacle growth. (a) Predicted energies available for production for Balanus glandula as a function of water temperature and velocity. Contour lines represent intervals of $5 \mathrm{~J}$ and black circles indicate environmental conditions used in the mesocosm experiment. (b) Comparison of predicted energy for production versus measured barnacle growth in mesocosm experiment. Growth was assessed at $11.5^{\circ} \mathrm{C}$ (open symbols), $14{ }^{\circ} \mathrm{C}$ (filled symbols), $2 \mathrm{~cm} \mathrm{~s}^{-1}$ (circles), and $19 \mathrm{~cm} \mathrm{~s}^{-1}$ (squares) (From Nishizaki and Carrington 2015) (Copyright release pending) 
Respiration rates are potentially limited by: the transport rates of dissolved oxygen from the water column to the surface of a barnacle (known as mass transfer limitation); reaction kinetics at the boundary that limit the ability of an organism to transport oxygen across the body wall (reaction kinetic limitation); or a combination of both (Patterson and Sebens 1989; Sebens et al. 2003). Knowing whether uptake rates are governed by mass transfer versus kinetic limitation is important for understanding whether physiological processes are regulated by factors internal versus external to the organism. In barnacles, respiration is mass transfer limited under low water velocity-high temperature conditions (Fig. 6). In contrast, limitation by uptake reaction kinetics, when the capacity of barnacles to uptake and process oxygen is slower than its physical delivery by mass transport, prevails under high flow-low temperature conditions. Moreover, there are intermediate flow-temperature conditions where both mass transfer and kinetic limitation are important (Nishizaki and Carrington 2014b). This suggests that, in slow-moving water, respiration may become mass transfer limited as temperatures rise, whereas faster flows could serve to ameliorate the effects of elevated temperatures.

\subsubsection{Energy Budgets and Growth}

An annual energy budget for the barnacle Balanus glandula has been constructed to predict the production of body tissue, gametes, shell, aquatic and aerial respiration, molting, and fecal production. This approach demonstrated that although individual barnacles show greater production compared to crowded barnacles, at the population level, crowding results in higher productivity on a per area basis (Wu 1980), and thus greater secondary production available to higher trophic levels.

A simple energy budget model based on feeding and respiration response curves predicts peak growth at moderate temperatures and velocities (Fig. 7; Nishizaki and Carrington 2015). These predictions were consistent with growth data collected under ecologically relevant thermal and flow experimental conditions. An advantage of this type of approach is that it provides a mechanistic understanding of the behavioral and physiological processes underlying growth. For instance, low growth is expected at both low and high velocities due to lower encounter rates with suspended food particles and lower capture efficiencies, respectively. At high temperatures, growth is likely limited by high metabolic costs, whereas low growth at low temperatures may be a consequence of low oxygen availability (Verberk and Atkinson 2013) and/or slow cirral beating and low feeding rates.

Temperature may influence growth both through changes in physiology and changes in mechanics, via the viscosity of seawater. However, Verberk and Atkinson (2013) also suggest that the availability of oxygen may actually decrease at lower temperatures due to lower oxygen partial pressure, which may ultimately serve as a limit to body size. At high temperatures, elevated metabolic demand may be counterbalanced when high water velocity promotes the exchange of gases and nutrients that sustain metabolism. Moreover, these results advocate for approaches that consider the combined effects of multiple stressors and suggest that both increases and decreases in temperature or flow impact barnacle growth but through different physiological and behavioral mechanisms. 
Gonad development shows a seasonal pattern that suggests temperature may be an important determining factor. Warm temperatures are generally associated with earlier reproductive maturation and a greater proportion of adults that are ultimately reproductively active. Experimental data for B. glandula in a mesocosm and field study confirm that barnacles show greater gonad production under higher temperatures and faster water velocities (Nishizaki and Carrington 2015). Gonad production is also influenced by crowding, as egg production from individual barnacles was 2.5 times higher compared to crowded individuals ( $\mathrm{Wu} 1980)$.

Acknowledgments The University of Washington Friday Harbor Laboratories and Department of Biology supplied facilities for this research. PRIN TETRIS 2010 grant (n. 2010PBMAXP_003) funded to Gianluca Sarà by the Italian Minister of Research and University (MIUR) supported this research. NSF grant OCE 0850809 supported research by K. Sebens.

\section{References}

Anderson DT, Southward AJ. Cirral activity of barnacles. In: Barnacle biology. Rotterdam, Netherlands: A.A. Balkema Press; 1987. p. 135-74.

Anthony KRN, Fabricius KE. Shifting roles of heterotrophy and autotrophy in coral energetics under varying turbidity. J Exp Mar Biol Ecol. 2000;252:221-53.

Arsenault DJ, Marchinko KB, Palmer AR. Precise tuning of barnacle leg length to coastal wave action. Proc R Soc Lond B Biol Sci. 2001;268:2149-54.

Bayne BL, Widdows J. The physiological ecology of two populations of Mytilus edulis L. Oecologia. 1978;37:137-62.

Berkes F. Implementing ecosystem-based management: evolution or revolution? Fish Fish. 2012;13:465-76.

Bertness MD, Gaines S, Yeh SM. Making mountains out of barnacles: the dynamics of acorn barnacle hummocking. Ecology. 1998;79:1382-94.

Bingham BL, Dimond JL, Muller-Parker G. Symbiotic state influences life-history strategy of a clonal cnidarian. Proc R Soc B. 2014;281:20140548. doi:10.1098/rspb.2014.0548.

Buckeridge JS. Opportunism and the resilience of barnacles (Cirripedia: Thoracica) to environmental change. Integr Zool. 2012;7:137-46.

Carrington E, Waite HJ, Sarà G, Sebens KP. Mussels as a model system for integrative ecomechanics. Ann Rev Mar Sci. 2015;7:9.10-27.

Castilla JC, Guinez RG, Alvarado JL, Pacheco C, Varas M. Distribution, population structure, population biomass and morphological characteristics of the tunicate Pyura stolonifera in the Bay of Antofagasta, Chile. Mar Ecol. 2000;21:161-74.

Chapman DS, et al. Modelling the introduction and spread of non-native species: international trade and climate change drive ragweed invasion. Glob Chang Biol. 2016. doi:10.1111/gcb.13220.

Coma R, Gili JM, Zabala M, Riera T. Feeding and prey capture cycles in the aposymbiotic gorgonian Paramuricea clavata. Mar Ecol Prog Ser. 1994;115:257-70.

Coma R, Ribes M, Gili JM, Zabala M. An energetic approach to the study of life-history traits of two modular colonial benthic invertebrates. Mar Ecol Prog Ser. 1998;162:89-103.

Denny MW. Biology and the mechanics of the wave-swept environment. Princeton: Princeton University Press; 1988, 344 pp.

Fabricius KE, Yahel G, Genin A. In situ depletion of phytoplankton by an azooxanthellate soft coral. Limnol Oceanogr. 1998;43:354-6.

Ferrier-Pagès C, Witting J, Tambutté E, Sebens KP. Effect of natural zooplankton feeding on the tissue and skeletal growth of the scleractinian coral Stylophora pistillata. Coral Reefs. 2003;22:229-40. 
Galloway AWE, Lowe AT, Sosik EA, Yeung YS, Duggins DO. Fatty acid and stable isotope biomarkers suggest microbe-induced differences in benthic food webs between depths. Limnol Oceanogr. 2013;58:1452-62.

Geierman C, Emlet R. Feeding behavior, cirral fan anatomy, Reynolds numbers, and leakiness of Balanus glandula, from post-metamorphic juvenile to the adult. J Exp Mar Biol Ecol. 2009;379:68-76.

Gilman S, Wong J, Chen S. Oxygen consumption in relation to body size and cirral beat behavior in the barnacle, Balanus glandula. J Crustac Biol. 2013;33:317-22.

Hamaoui-Laguel L, et al. Effects of climate change and seed dispersal on airborne ragweed pollen loads in Europe. Nat Clim Chang. 2015;5:766-71.

Helmuth BST, Sebens KP, Daniel TL. Morphological variation in coral aggregations: branch spacing and mass flux to coral tissues. J Exp Mar Biol Ecol. 1997;209:233-59.

Houlbrèque F, Ferrier-Pagès C. Heterotrophy in tropical scleractinian corals. Biol Rev Camb Philos Soc. 2009;84:1-17. doi:10.1111/j.1469-185X.2008.00058.x.

Houlbrèque F, Reynaud S, Godinot $\mathrm{C}$, Oberhänsli $\mathrm{F}$, Rodolfo-Metalpa R, Ferrier-Pagès C. Ocean acidification reduces feeding rates in the scleractinian coral Stylophora pistillata: Acidification and Stylophora nutrition. Limnol Ocean. 2015;60:89-99.

Hughes RN, Lewis $\mathrm{AH}$. On the spatial distribution, feeding and reproduction of the vermetid gastropod Dendropoma maximum. J Zool. 2009;172:531-47. doi:10.1111/j.1469-7998.1974. tb04383.x.

Jumars P. Concepts in biological oceanography; an interdisciplinary primer. Oxford: Oxford University Press; 1993, 368 pp.

Koehl MAR, Strickler JR. Copepod feeding currents: food capture at low Reynolds number. Limnol Oceanogr. 1981;26:1062-73.

Kooijman SALM. Dynamic energy budget theory for metabolic organisation. 3rd ed. Cambridge: Cambridge University Press; 2010, 508pp.

LaBarbera M. Feeding currents and particle capture mechanisms in suspension feeding animals. Am Zool. 1984;24:71-84.

Lang JC, Chornesky EA. Competition between scleractinian reef corals- a review of mechanisms and effects. In: Dubinsky Z, editor. Coral reefs, Ecosystems of the World 25. Amsterdam: Elsevier; 1990. p. 209-52.

Li NK, Denny MW. Limits to phenotypic plasticity: flow effects on barnacle feeding appendages. Biol Bull. 2004;206:121-4.

Matzelle A, Montalto V, Sarà G, Zippay M, Helmuth B. Application of the covariation method for Dynamic Energy Budget model parameterization of the bivalve Mytilus californianus. J Sea Res. 2014;94:105-10.

Mills MM, Sebens KP. Ingestion and assimilation of nitrogen from benthic sediments by three species of corals. Mar Biol. 2005;145:1097-106.

Munroe DM, Klinck JM, Hofmann EE, Powell EN. The role of larval dispersal in metapopulation gene flow: local population dynamics matter. J Mar Res. 2012;70:441-67.

Neufeld CJ, Rankine C. Cuticle and muscle variation underlying phenotypic plasticity in barnacle feeding leg and penis form. Invertebr Biol. 2012;131:96-109.

Nishizaki MT, Carrington E. Behavioral responses to water flow and temperature influence feeding in the barnacle, Balanus glandula. Mar Ecol Prog Ser. 2014a;507:207-18.

Nishizaki MT, Carrington E. The effect of water temperature and flow on respiration in barnacles: patterns of mass transfer versus kinetic limitation. J Exp Biol. 2014b;217:2101-9.

Nishizaki MT, Carrington E. The effect of water temperature and velocity on barnacle growth: quantifying the impact of multiple environmental stressors. J Therm Biol. 2015. doi:10.1016/j. jtherbio.2015.02.002.

Okamura B, Partridge JC. Suspension feeding adaptations to extreme flow environments in a marine bryozoan. Biol Bull. 1999;196:205-15.

Pacifici M, Foden WB, Visconti P, Watson JEM, Butchart SHM, Kovacs KM, Scheffers BR, Hole DG, Martin TG, Akçakaya HR, Corlett RT, Huntley B, Bickford D, Carr JA, Hoffmann AA, 
Midgley GF, Pearce-Kelly P, Pearson RG, Williams SE, Willis SG, Young B, Rondinini C. Assessing species vulnerability to climate change. Nat Clim Chang. 2015;5:215-24.

Palardy JE, Grottoli AG, Matthews KA. Effect of naturally changing zooplankton concentrations on feeding rates of two coral species in the Eastern Pacific. J Exp Mar Biol Ecol. 2006;331:99-107.

Patterson MR, Sebens KP. Forced convection modulates gas exchange in cnidarians. Proc Natl Acad Sci. 1989;86:8833-6.

Patterson MR, Sebens KP, Olson RR. In situ measurements of forced convection on primary production and dark respiration in reef corals. Limnol Oceanogr. 1991;36:936-48.

Pikitch EK, et al. Ecosystem-based fishery management. Science. 2004;305:346-7.

Pusceddu A, Dell'Anno A, Danovaro R, Manini E, Sarà G, Fabiano M. Enzymatically hydrolyzable protein and carbohydrate sedimentary pools as indicators of the trophic state of detritus sink systems: a case study in a Mediterranean coastal lagoon. Estuaries. 2003;26:641-50.

Ribes M, Coma R, Gili JM. Heterotrophic feeding by gorgonian corals with symbiotic zooxanthella. Limnol Oceanogr. 1998;43:1170-9.

Richter R, et al. How to account for habitat suitability in weed management programmes? Biol Invasions. 2013;15:657-69.

Romero MR, Kelstrup HCP, Strathmann RR. Capture of particles by direct interception by cilia during feeding of a gastropod veliger. Biol Bull. 2010;218:145-59.

Rubenstein DI, Koehl MAR. The mechanisms of filter feeding: some theoretical considerations. Am Nat. 1977;111:981-94.

Sanford E. The feeding, growth, and energetics of two rocky intertidal predators (Pisaster ochraceus and Nucella canaliculata) under water temperatures simulating episodic upwelling. J Exp Mar Biol Ecol. 2002;273:199-218.

Sanford E, Menge BA. Spatial and temporal variation in barnacle growth in a coastal upwelling system. Mar Ecol Prog Ser. 2001;209:143-57.

Sarà $\mathrm{G}$, Kearney M, Helmuth $\mathrm{B}$. Combining heat-transfer and energy budget models to predict local and geographic patterns of mortality in Mediterranean intertidal mussels. Chem Ecol. 2011;27:135-45.

Sarà G, Reid G, Rinaldi A, Palmeri V, Troell M, Kooijman SALM. Growth and reproductive simulation of candidate shellfish species at fish cages in the southern Mediterranean: Dynamic Energy Budget (DEB) modelling for integrated multi-trophic aquaculture. Aquaculture. 2012;324-325:259-66.

Sarà G, Palmeri V, Montalto V, Rinaldi A, Widdows J. Parameterisation of bivalve functional traits for mechanistic eco-physiological Dynamic Energy Budget (DEB) models. Mar Ecol Prog Ser. 2013a;480:99-117.

Sarà G, Palmeri V, Rinaldi A, Montalto V, Helmuth B. Predicting biological invasions in marine habitats through eco-physiological mechanistic models: a study case with the bivalve Brachidontes pharaonis. Divers Distrib. 2013b;19:1235-47.

Sarà G, Milanese M, Prusina I, Sarà A, Angel DL, Glamuzina B, Nitzan T, Freeman S, Rinaldi A, Palmeri V, Montalto V, Lo Martire M, Gianguzza P, Arizza V, Lo Brutto S, De Pirro M, Helmuth B, Murray J, De Cantis S, Williams GA. The impact of climate change on Mediterranean intertidal communities: losses in coastal ecosystem integrity and services. Reg Environ Chang. 2014a; 14:5-17.

Sarà G, Rinaldi A, Montalto V. Thinking beyond organism energy use: a trait based bioenergetic mechanistic approach for predictions of life history traits in marine organisms. Mar Ecol. 2014b;35:506-15.

Sebens KP. The energetics of asexual reproduction and colony formation in benthic marine intertebrates. Am Zool. 1979;19:683-97.

Sebens KP. The limits to indeterminate growth: an optimal size model applied to passive suspension feeders. Ecology. 1982;82:209-22.

Sebens KP. Chapter 4: Coelenterate energetics. In: Pandian TJ, Vernberg FJ, editors. Animal energetics. New York: Academic; 1987a. p. 55-120. 
Sebens KP. The ecology of indeterminate growth in animals. Annu Rev Ecol Syst. 1987b;18:371-407.

Sebens KP, Koehl MAR. Predation on zooplankton by the benthic anthozoans Alcyonium siderium (Alcyonacea) and Metridium senile (Actiniaria) in the New England subtidal. Mar Biol. 1984;81:255-74.

Sebens KP, Witting J, Helmuth B. Effects of water flow and aggregation on particle capture by the reef coral Madracis mirabilis. J Exp Mar Biol Ecol. 1996a;211:1-28.

Sebens KP, Vandersall K, Savina L, Graham K. Zooplankton capture by two scleractinian corals, Madracis mirabilis and Montastrea cavernosa, in a field enclosure. Mar Biol. 1996b;127:303-18.

Sebens, KP. Adaptive responses to water flow: morphology, energetics, and distribution of reef corals. Proceedings of the 8th International Coral Reef Symposium, Panama City (1996); 1997; 2:1053-8.

Sebens KP, Grace S, Helmuth B, Maney E, Miles J. Water flow and prey capture by three scleractinian corals, Madracis mirabilis, Montastrea cavernosa and Porites porites in a field enclosure. Mar Biol. 1998;131:347-60.

Sebens KP. Energetic constraints, size gradients and size limits in benthic marine invertebrates. Integr Comp Biol. 2002;42:853-61.

Sebens KP, Helmuth B, Carrington E, Agius B. Effects of water flow on growth and energetics of the scleractinian coral Agaricia tenuifolia, in Belize. Coral Reefs. 2003;22:35-47.

Shimeta J, Jumars PA. Physical-mechanisms and rates of particle capture by suspension-feeders. Oceanogr Mar Biol. 1991;29:191-257.

Trager GC, Hwang JS, Strickler JR. Barnacle suspension-feeding in variable flow. Mar Biol. 1990;105:117-27.

Verberk WCEP, Atkinson D. Why polar gigantism and Palaeozoic gigantism are not equivalent: effects of oxygen and temperature on the body size of ectotherms. Funct Ecol. 2013;27:127585.

Vogel S. Life in moving fluids: the physical biology of flow, 2nd rev ed. Princeton: Princeton Paperbacks; 1996. 484 pp.

Warren CE, Davis GE. Laboratory studies on the feeding, bioenergetics, and growth of fish. In: Gerking SD, editor. The biological basis of freshwater fish production. Oxford: Blackwell; 1967. p. 175-214.

Wellington GM. An experimental analysis of the effects of light and zooplankton on coral zonation. Oecologia. 1982;52:311-20.

Wildish D, Kristmanson D. Benthic suspension feeders and flow. Cambridge: Cambridge University Press; 2005, 424 pp.

Wu RSS. Effects of crowding on the energetics of the barnacle Balanus glandula Darwin. Can J Zool. 1980;58:559-66. 